\title{
Autoignition of Methyl Butanoate Under ENGine RELEVANT CONDITIONS
}

\author{
Kamal Kumar ${ }^{1,2}$ and Chih-Jen Sung ${ }^{1}$ \\ ${ }^{1}$ Department of Mechanical Engineering, University of Connecticut, Storrs, CT 06269 \\ ${ }^{2}$ Department of Mechanical Engineering, University of Idaho, Moscow, ID 83844
}

Keywords: Methyl Butanoate, Autoignition, Rapid Compression Machine, Bio-diesel, Surrogate Fuel

Corresponding Author:

Kamal Kumar

Department of Mechanical Engineering

University of Idaho

Moscow, ID 83844, USA

E-Mail: kkumar@uidaho.edu

Phone: (208) 885-6263

Submitted for publication in Combustion and Flame

Revised: April 8, 2016

Manuscript Reference Number: CNF-D-15-00147R1 


\title{
Autoignition of Methyl Butanoate Under ENGine RELEVANT CONDITIONS
}

\author{
Kamal Kumar ${ }^{1,2}$ and Chih-Jen Sung ${ }^{1}$ \\ ${ }^{1}$ Department of Mechanical Engineering, University of Connecticut, Storrs, CT 06269 \\ ${ }^{2}$ Department of Mechanical Engineering, University of Idaho, Moscow, ID 83844
}

\begin{abstract}
This study reports the autoignition delay times of methyl butanoate in argon-air (i.e. $\mathrm{Ar} / \mathrm{O}_{2}=3.76$ by mole) mixtures under thermodynamic conditions relevant to compression ignition engines, using a rapid compression machine (RCM). The ignition delay times were obtained for the compressed temperature range of 833-1112 K and compressed pressures corresponding to 15 , 30, 45, and 75 bar. In addition, the effect of fuel mole fraction on ignition delay times were experimentally studied by covering equivalence ratios corresponding to $0.25,0.5$, and 1.0 under realistic fuel loadings without additional dilution. For the range of conditions investigated, the ignition delay times exhibit an Arrhenius dependence on temperature and an inverse relationship with the compressed pressure. No evidence of two-stage ignition was observed in the current experiments, nor was a negative temperature coefficient trend seen in the ignition delay times. The experimental results were compared to zero-dimensional simulations taking into account the full compression stroke and the heat loss characteristics of the RCM, using chemical kinetic models reported in the literature. The literature models were found to predict significantly higher reactivity when compared to the current experiments. Chemical kinetic analysis was then conducted to identify the reactions responsible for the mismatch between the experiments and the simulated results. Key reactions that could help obtain a better match between the experimental and simulated results were identified using both brute-force and global sensitivity analyses. In view of the large uncertainties associated with the low-temperature chemistry of methyl butanoate, further studies are needed to update the kinetic parameters of the key reactions in order to improve the model comprehensiveness.
\end{abstract}




\section{Introduction}

The proportion of renewable fuels used for the transportation sector is projected to be approximately $14 \%$ of the marketed renewable energy consumption by the year 2020 [1]. Combustion in engines is the predominant mode of obtaining energy from biofuels for the purpose of transportation. One of the important chemical compound classes that constitute biodiesel is methyl esters [2]. It is therefore of fundamental and practical significance to develop a basic understanding of the combustion properties of methyl esters. Of particular interest is the autoignition response, which is the fundamental basis for classification of diesel fuels in terms of their cetane numbers. The ability to predict both the global combustion properties and the detailed species evolutions during pyrolysis/oxidation of methyl esters is essential to their efficient and clean utilization in internal combustion engines. The development of predictive capabilities requires both computational and experimental efforts. An important component of the computational efforts is the availability of a detailed reaction mechanism describing the sequence of elementary reactions that model the fuel decomposition and oxidation. The development of a comprehensive reaction mechanism can be greatly aided by fundamental experimental data derived from various complementary, well-characterized laboratory experiments covering a wide range of thermophysical conditions. Such fundamental combustion experiments provide a reliable test bed for mechanism validation.

As an experimental effort in supporting the development of detailed reaction mechanisms of methyl esters, this work reports experimental data on the autoignition delay times of methyl butanoate under thermodynamic conditions that are of relevance to engine combustion. Methyl butanoate belongs to the class of compounds that occur in biodiesel. It has been used as a biodiesel surrogate component to further the understanding of methyl ester combustion kinetics 
[3-10]. It is well established that chemical kinetic models have a hierarchical structure in terms of carbon numbers [11]. Therefore, methyl butanoate (and lower methyl esters) oxidation kinetics need to be fully understood as a part of the development of kinetic schemes for real biodiesel. In addition to providing experimental autoignition results under previously unreported conditions, we compared the newly-obtained experimental results to computational predictions using various reaction mechanisms reported in the literature. Both a global sensitivity analysis and a brute-force one-at-a-time sensitivity analysis were further performed on the computational results to identify the reaction steps influencing the computed ignition delay times. In the following, we highlight the experimental and modeling studies on methyl butanoate reported in the literature.

The autoignition of methyl butanoate has been previously studied using a rapid compression machine (RCM) by Dooley et al. [12] for equivalence ratios in the range of $\phi=0.33-1.0$, pressures of 10, 15, 20, and 40 atmospheres, and a temperature span of $640-949 \mathrm{~K}$. The work of Dooley et al. [12] varied the proportion of oxygen in the oxygen-inert mixture to obtain the results for $\phi=0.33$. The low-temperature autoignition of stoichiometric methyl butanoate mixtures has also been previously reported by HadjAli et al. [13] for a temperature span of $815 \pm 20 \mathrm{~K}$ and pressures between 15.5 and 20.5 bar, using an RCM. In addition, Walton et al. [14] have reported the ignition delay times for methyl butanoate for equivalence ratios of $0.3-0.4$, a pressure range of $4.7-19.6 \mathrm{bar}$, and temperatures varying from $935 \mathrm{~K}$ to $1117 \mathrm{~K}$, using a rapid compression facility. In Walton et al. [14], the total inert-to-oxygen molar ratio was kept 3.76 , while the inert gases ( $\mathrm{Ar}$ or $\mathrm{O}_{2}$ ) were varied.

Compared to the literature RCM studies, the current work explores an equivalence ratio that is leaner and covers a range of $\phi=0.25-1.0$. This work has a fixed inert-to-oxygen proportion 
corresponding to $\mathrm{Ar} / \mathrm{O}_{2}$ molar ratio of 3.76 for all equivalence ratios. Further, the current $\mathrm{RCM}$ study extends the compressed pressures up to 75 bar and the compressed temperatures up to $1112 \mathrm{~K}$

Autoignition of methyl butanoate has also been studied in the shock tube apparatus. AkihKumgeh and Bergthorson [15] studied the high temperature autoignition of methyl butanoate behind reflected shocks. Their measurements were carried out for the equivalence ratios of $0.5,1.0$, and 2.0. The proportion of oxygen in the oxidizer varied between 2.79 and $20.6 \%$. The pressures and temperatures in their study were in the range of $1-10 \mathrm{~atm}$ and $1024-1715 \mathrm{~K}$, respectively. Davidson et al. [16] carried out shock-tube ignition delay measurements on normal alkanes and simple oxygenates, which included methyl butanoate. The fuels were tested for equivalence ratios of $\phi=0.4-2.0$, temperatures of $1150-1550 \mathrm{~K}$, and for pressures in the range of 1-4 atm. Hakka et al. [17] reported the ignition delay times for methyl butanoate behind reflected shocks for equivalence ratios of $0.25,1.0$, and 2.0, for pressures around 8 atm, and in the temperature range of $1250-2000 \mathrm{~K}$. Another study by Akih-Kumgeh and Bergthorson [18] explored the structure-reactivity trends for alkanoic acid methyl esters, including methyl butanoate, using high temperature shock tube ignition and quantum chemical calculations. The shock tube apparatus has also been employed to study the decomposition and pyrolysis for methyl esters in the studies by Farooq et al. [19, 20]. Overall rate constants for reactions of the hydroxyl radical with methyl esters, including methyl butanoate, were studied using a shock tube by Lam et al. [21].

Experimental studies on the oxidation of methyl butanoate have also been conducted by Sarathy et al. [22] both in a jet stirred reactor and an opposed flow diffusion flame. Their study investigated the effect of chemical structure on the combustion of $C_{4}$ fatty methyl esters, and 
compared the levels of stable intermediate for methyl butanoate and methyl crotonate [22]. Another study by Gail et al. [23] also examined the effect of unsaturation on the combustion of fatty acid methyl esters in a jet stirred reactor and a counterflow diffusion flame. This study by Gaïl et al. [23] used methyl butanoate as the representative saturated fuel, and proposed a detailed chemical kinetic model.

In addition, methyl butanoate has been studied in the context of internal combustion engine applications. The decomposition of a biodiesel surrogate $\mathrm{C}_{19} \mathrm{H}_{34} \mathrm{O}_{2}$ was assumed to yield $n$ heptane, methyl butanoate, and phenyl methyl ester in a combustion modeling study for internal combustion engine applications by Golovitchev and Yang [24]. A numerical study by Um and Park [25] used a combination of a reduced methyl butanoate mechanism and a reduced $n$-heptane mechanism to model the ignition and combustion of biodiesel. Som et al. [26] have used methyl butanoate as a surrogate for soy biodiesel in their study of injector flow and spray characteristics for bio- and petro-diesel. Ra and Reitz [27] used methyl butanoate as a component in a multicomponent surrogate reaction mechanism to simulate engine combustion with multi-component fuels. There are several other studies that have used methyl butanoate based kinetic schemes in numerical investigations on engine combustion, e.g., [6, 28-31]. Boehman and co-workers have carried out motored engine experiments on esters and blends of esters with other fuels [32-35]. A study by Zhang and Boehman [32] examined the autoignition of binary fuel blends of $n$-heptane and $\mathrm{C}_{7}$ esters in a modified CFR engine for a range of compressions ratios that was relevant to HCCI operation. Zhang and Boehman [33] also conducted a study on the autoignition of blends of ethyl and methyl esters, as well as $\mathrm{C}_{9}$ fatty acid esters, in motored engines.

Furthermore, methyl butanoate has been the subject of fundamental studies related to premixed [36-42] and non-premixed [7, 22, 39, 40, 43] combustion environments. It has also 
been studied in droplet combustion [44] and soot formation experiments [45, 46]. Additionally, there have been theoretical efforts towards developing an understanding of the thermodynamic and chemical kinetic parameters associated with this methyl ester [4, 47-51].

\section{Experimental Specifications}

Autoignition experiments reported in this work were carried out using an RCM, with provision for preheating. The RCM compresses a fixed mass of premixed fuel-oxidizer mixture from a given initial state $\left(T_{0}, P_{0}\right)$ to a state at the end of compression $\left(T_{C}, P_{C}\right)$. The state at the

end of compression is related to the initial state through the equation: $\int_{T_{0}}^{T_{C}} \frac{\gamma}{\gamma-1} \frac{d T}{T}=\ln \left(\frac{P_{C}}{P_{0}}\right)$. Note that the specific heat ratio $\gamma$ in the equation is a function of temperature. Here, the values of $T_{0}$, $P_{0}$, and $P_{C}$ are experimentally measured, while the compressed temperature $T_{C}$ is deduced using the aforementioned equation. A recent study [52] using two-line thermometry in an almost identical RCM has demonstrated that the simulated and experimental temperature data are within $5 \mathrm{~K}$ during the induction period. The dynamic pressure measurement during the compression stroke and the subsequent interval was carried out using an uncoated, thermal shock-resistant Kistler 6125B pressure transducer with a 5010B charge amplifier. Further details on the operation of the RCM were documented in an earlier study [53].

In the present study, ignition delay times were deduced from the pressure-time records, with the end of compression serving as the reference time $(t=0)$. The maximum rate of pressure rise in the post-compression pressure trace is identified as the ignition event [54]. The premixed fueloxidizer mixture used in this study had an initial temperature varying between 300 and $323 \mathrm{~K}$. Methyl butanoate (99\% assay) obtained from Sigma-Aldrich was used as the fuel in these RCM experiments. The oxidizer consisted of high purity oxygen (99.994\%) and argon (99.999\%) in a 
molar proportion of 1:3.76. The gaseous components were blended manometrically in a vessel of known volume, and liquid fuel by weight was added by means of syringe via a septa. The mixture composition, experimental conditions (in terms of measured $P_{C}$ and estimated $T_{C}$ ), measured ignition delay results, and uncertainty associated with the ignition delay data are provided in Table. 1. Moreover, the ignition delay uncertainty listed in Table 1 was determined based on the standard deviation of the measured values from the repeated runs. Each experimental data point was repeated at least twice, and more than $75 \%$ of the experimental points were repeated three times. The maximum standard deviation for the ignition delay times in the experiments was 3.97 milliseconds.

\section{Computational Specifications}

Computed ignition delay results reported in this work have been obtained using the CHEMKIN-III [55] package along with SENKIN [56]. Initial conditions, in the form of the reactant composition, pressure $\left(P_{0}\right)$, and temperature $\left(T_{0}\right)$, were specified as inputs. The RCM experiments were simulated by specifying the reactor volume as a function of time during the compression stroke. The post compression effects were modeled empirically to reproduce the pressure drop effect observed on account of heat loss from the reactor walls. For each reactive experimental condition, the volume time-history profile used in the simulation was deduced based on the corresponding non-reactive experiment by replacing $\mathrm{O}_{2}$ with $\mathrm{N}_{2}$, as discussed in [53]. The objective of accounting for the heat loss effect is to match the non-reactive experimental and computed pressure traces by including a volume expansion term in the simulations. Details of the heat loss modeling can be found in a prior work by Mittal and Sung [53]. All the volume time-histories associated with this study are provided as supplementary material for simulating the present RCM experiments. It is further noted that the zero 
dimensional simulations do not attempt to model the heat loss effect after ignition.

The chemical kinetic models used to simulate the RCM experimental results have been obtained from the studies by Fisher et al. [57], Gaïl et al. [58], Dooley et al. [12], Hakka et al. [17], Dievart et al. [59], and Liu et al. [5].

\section{$4 \quad$ Results and Discussion}

\subsection{Experimental}

The experimental ignition delay times for methyl butanoate for various equivalence ratios with compressed pressure as a parameter are shown in Fig. 1. As demonstrated in Fig. 1(a), the current experimental data set has been obtained for compressed pressures of $P_{C}=15,30$, 45, and 75 bar, corresponding to a fuel lean condition of equivalence ratio equal to 0.25 . Figures 1 (b) and 1(c) show the ignition delay times for equivalence ratios corresponding to 0.5 and 1.0, respectively, and each contains results for compressed pressures of $P_{C}=15$ and 30 bar. The plots in Figs. 1(a)-1(c) show that the ignition delay times exhibit an Arrhenius dependence as a function of temperature. It can also be seen that the ignition delay times decrease with increasing pressure. Furthermore, for a given pressure the ignition delay times obtained under the current experimental conditions exhibit a monotonic trend with temperature variation. No evidence of negative temperature coefficient (NTC) like behavior is observed for the current experimental conditions.

Selected experimental pressure traces corresponding to the ignition delay times shown in Fig. 1 for $\phi=0.25$ are plotted in Figs. 2(a)-2(d). The pressure traces for the current experimental conditions show a single hot ignition event, without any indication of first stage pressure rise. The lack of a first-stage pressure rise or two-stage ignition response could be the 
result of the relatively high temperature conditions $\left(T_{C}>833 \mathrm{~K}\right)$ for the current experiments. The influence of equivalence ratio, also representing the fuel loading effect herein, on the ignition delay time at a fixed compressed pressure $\left(P_{C}=30\right.$ bar $)$ and a nearly constant compressed temperature $\left(T_{C} \approx 911 \mathrm{~K}\right)$ is shown in Fig. 3 . The experimental pressure traces in Fig. 3 show that the ignition delay times decrease with an increase in the equivalence ratio range of $\phi=0.25-1.0$. There is sharper change in ignition delay time in the fuel lean region between the equivalence ratios of $\phi=0.25-0.5$, as compared to that between the equivalence ratios of $\phi=0.5-1.0$. It is seen from the pressure traces in Fig. 3 that the general characteristic of the ignition process is similar for all the three equivalence ratios, namely exhibiting a single hot ignition event without any first-stage activity.

The influence of the variables impacting the ignition delay times, for the complete set of current data, can be represented quantitatively in the form of a correlation. The data set shown in the correlation corresponds to a temperature range of $T_{C}=833-1112 \mathrm{~K}$, a pressure range of $P_{C}=15-75$ bar, an equivalence ratio range of $\phi=0.25-1.0$, and an argon to oxygen molar ratio of 3.76 in the oxidizer. The current ignition delay data are fit to a correlation of the form,

$$
\tau=\propto\left(X_{\text {Fuel }}\right)^{a}\left(P_{C}\right)^{n} \exp \left(T_{a} / T_{c}\right) .
$$

In this form of the correlation, $\tau$ is the ignition delay time in milliseconds, $X_{F u e l}$ in the mole fraction of the fuel component, $P_{C}$ is the compressed charge pressure in bar, and $T_{c}$ is the compressed charge temperature in Kelvin. The activation temperature in Kelvin is given by $T_{a}$. Moreover, the fuel and pressure exponents are given by $a$ and $n$, respectively, and $\alpha$ is a constant with appropriate units. The results of such a fitting are shown in Fig. 4, where the empty circles represent the experimental data points and the line represents the fit. Note that the vertical axis in Fig. 4 represents a normalized form of the above correlation given by $\frac{\tau}{\left[\left(X_{F u e l}\right)^{a}\left(P_{C}\right)^{n}\right]}=$ 
$\alpha \exp \left(T_{a} / T_{c}\right)$. The value of the activation energy deduced from the fit for the current experimental data is $46.1 \mathrm{kcal} / \mathrm{mol}$. Previous ignition studies by Akih-Kumgeh and Bergthorson [18], Hakka et al. [17], and Walton et al. [14, 60], have reported activation energies of 38.1, 55.6, and $30.3 \mathrm{kcal} / \mathrm{mol}$, respectively.

\subsection{Computational}

The experimental results presented in the previous section were further compared to simulated values obtained using chemical kinetic models available in the literature. As noted earlier, we compared our experimental results against the chemical kinetic schemes of Fisher et al. [57], Gaïl et al. [58], Dooley et al. [12], Hakka et al. [17], Dievart et al. [59], and Liu et al. [5]. The result of such a comparison for a selected condition $\left(\phi=0.5, P_{C}=30 \mathrm{bar}, T_{C}=\right.$ $904 \mathrm{~K}$ ) is shown in Fig. 5. The comparison is presented in the form of pressure traces for the experimental condition and the corresponding simulations obtained using the aforementioned chemical kinetic models. It can be seen from Fig. 5 that the models in general are quite reactive, thereby predicting shorter ignition delays, compared to the current experimental result. The simulated pressure trace obtained using the model of Hakka et al. [17] is closest to the experimental results, while it under-predicts the experimental value by a factor of $\sim 2.7$ under the condition shown in Fig. 5. The simulated pressure traces obtained using the other chemical kinetic schemes are significantly faster compared to the experimental results.

The ranking of the relative reactivity for the various models shown in Fig. 5 for a specific condition carries over to the other conditions studied in this work, as can be seen in Figs. 6(a)6(c). The comparison in the form of an Arrhenius plot shown in Fig. 6(a) is for the case corresponding to the leanest fuel-oxidizer mixture and the highest pressure, i.e. $\phi=0.25$ and $P_{C}=75$ bar. It can be seen from Fig. 6(a) that the model of Hakka et al. [17] is closest to the 
experimental data over the entire temperature range followed by the model of Dooley et al. [12]. The results from the models of Fisher et al. [57], Gaïl et al. [58], and Dievart et al. [59] are quite similar, but faster compared to that of Dooley et al. [12]. On the other hand, the model of Liu et al. [5] is found to be the fastest amongst all, and is farthest from the current experimental results. Similar trends are also observed for other equivalence ratios and pressures as shown for $\phi=0.5$, $P_{C}=30$ bar and $\phi=1.0, P_{C}=15$ bar in Figs. 6(b) and 6(c), respectively. The most noticeable factor that emerges out of the comparisons shown in Figs. 5 and 6 is that the chemical kinetic model of Hakka et al. [17] is found to be closest to the experimental data, though it is still faster than the experiments. It is also noted that while the model of Dooley et al. [12] has been tested against some RCM experimental data, the agreement has not been as good. In addition, we merely used existing literature mechanisms for comparison with our experimental data, and hence proposing/developing a kinetic mechanism is beyond the scope of this work. Taking note of the above, we will henceforth limit our computational efforts, in terms of sensitivity and reaction pathway analyses to the particular scheme of Hakka et al. [17].

\section{Chemical Kinetic Analyses}

\subsection{Brute Force One-at-a-Time Sensitivity Analysis and Pathway Analysis}

The sensitivity of the computed ignition delay times to the variation of model parameters

(i.e. pre-exponential $A$ factors) was examined. The effects of doubling the $A$ factors, one at a time, in the model of Hakka et al. [17] was explored. The results of such a sensitivity analysis corresponding to an experimental data point at $\phi=0.5, P_{C}=30 \mathrm{bar}$, and $T_{C}=904 \mathrm{~K}$ are shown in Fig. 7(a), while the results for stoichiometric condition corresponding to another experimental data point at $P_{C}=30$ bar and $T_{C}=861 \mathrm{~K}$ are shown in Fig. 7(b). In Fig. 7, the 
length of each bar represents the percent change in ignition delay time due to the doubling and hence quantifies the degree of influence of an $A$ factor associated with a particular reaction. Positive values in Fig. 7 are used to represent an increase in the ignition delay times with increasing a pre-exponential factor, i.e. diminishing reactivity (longer ignition delay time). Negative values imply an increase in reactivity (shorter ignition delay time) as the $A$ factor for a particular reaction is doubled. It can be seen from Fig. 7 that the reaction of the parent fuel $\left(\mathrm{C}_{5} \mathrm{H}_{10} \mathrm{O}_{2} \mathrm{~S}-1\right.$ ) with the $\mathrm{HO}_{2}$ radical (Reaction 272) is the second most sensitive in the set, and it leads to shorter ignition delay times as its pre-exponential factor is increased. The reaction between the product radical formed from Reaction 272 (the aforementioned reaction) and molecular oxygen (Reaction 253) is the most sensitive one in Fig. 7, and it leads to an increase in ignition delay time with an increase in the pre-exponential factor. All reactions exhibiting a sensitivity magnitude of greater than $5 \%$ to one-at-a-time variation in their respective preexponential factors are also shown in Fig. 7.

It is noted that the ignition delay times computed in Fig. 7 to evaluate the sensitivity have been modeled to accommodate the full compression stroke and the post compression heat loss for the said data point. The computed pressure traces resulting from such a variation of the $A$ factors for the sensitive reactions are demonstrated in Fig. 8. Two vertical lines, one corresponding to the simulated nominal value for the original mechanism and one for the experimental ignition delay time, are also shown in Fig. 8 as a reference. Note that under the condition shown in Fig. 8 the predictions, based on the original and modified (by doubling the $A$ factor one at a time) mechanisms, are shorter than the experimental value.

A pathway analysis is also carried out for the model of Hakka et al. [17] under the initial conditions of pressure and temperature corresponding to that of the brute force sensitivity 
analysis in Fig. 7(a) (30 bar; $904 \mathrm{~K}$ ). In this constant-volume, adiabatic simulation, the key species consumption pathways that are active at a time corresponding to a $5 \mathrm{~K}$ temperature rise above the initial temperature of $904 \mathrm{~K}$ are shown in Fig. 9. The dotted red arrows indicate the two most sensitive reactions, i.e. Reaction 272 and Reaction 253 discussed earlier. The importance of the $\mathrm{HO}_{2}$ radical in the low temperature oxidation scheme is clearly seen from Fig. 9, given that it is next only to the $\mathrm{OH}$ radical in reactions involving the consumption of the fuel.

\subsection{Global Sensitivity Analysis}

The above brute force sensitivity analysis is local and linear in nature, as it is restricted to the response of a system (ignition delay time in the current study) to a single perturbation in a given chemical kinetic parameter set ( $A$ factors) at a specified condition. To further provide insights into the potential coupling of the parameters of key reactions and the most appropriate range for those key parameters, we used a well-established global sensitivity analysis method, based on the works of Cukier et al. [61], Schaibly et al. [62], McRae et al. [63], and Saltelli et al. [64], to study the ignition delay response due to the simultaneous variation in the input factors ( $A$ factors) for the baseline model. The classic fast package from the Joint Research Center of the European Commission [65] was adapted and modified for this analysis. The first step in conducting this analysis was to select the uncertain parameter. For this, we used the results of the brute force one-at-a-time sensitivity analysis shown in Fig. 7(a) and included all reactions that influence the magnitude of the ignition delay by $2.5 \%$ or more. A total of 32 reactions were found to satisfy this criterion for the model of Hakka et al. [17]. The next step was to assign an uncertainty factor to each of these reactions. The evaluated chemical kinetic data for combustion modeling supplement II by Baulch et al. [66] provided an assessment for error limits in the rate constant $k$. Although there were no recommendations on the error limits $(\Delta \log k)$ specific to the 
aforementioned 32 reactions, we assumed a $\Delta \log k= \pm 0.5$ for all 32 reactions. This value appears to be a reasonable assumption based on the listings in Table 4.1 for bimolecular reactions in the work of Baulch et al. [66]. As noted in the work of Baulch et al. [66], the assignment $\Delta \log k= \pm X$ implies that the range of $k$ covered by these error limits corresponds to $k_{\text {nominal }} / 10^{X}<$ Range $k<k_{\text {nominal }} \times 10^{X}$.

Having assumed the uncertainty range for the $A$ factors for the 32 reactions, the rate constant $k_{i}$ for these were associated to a frequency $\omega_{i}$ and a parameter $s$, as described in the work of Cukier et al. [61] and McRae et al. [63]. Each $k_{i}$ (via $A_{i}$ ) was assigned an incommensurate frequency $\omega_{i}$, based on the parameter set and procedures provided in the work of McRae et al. [63]. The parameter $s$ was set to vary between $-\pi / 2$ and $+\pi / 2$ as described in [63]. As noted by Saltelli at al. [64], the variation of $s$ allows all rate constants to vary at the same time as a 'search curve' traverses the space of the rate constants. A search curve of the form $k_{i}=G_{i}\left(\sin \left(\omega_{i} s\right)\right)$ needs to be defined [61, 63, 64]. We used a form of the search curve suggested by Saltelli et al. [64] given by $x_{i}=\frac{1}{2}+\frac{1}{\pi} \arcsin \left(\sin \left(\omega_{i} s\right)\right)$, which defines a straight line in the range of $(0,1)$. The minimum number of sample evaluations required is equal to $N_{s}=2 M \omega_{\max }+1[61,63,64]$, where $M$ is the interference factor, chosen to be equal to four in this study, and $\omega_{\max }$ is the maximum of all $\omega_{i}$ 's. This corresponds to a minimum of $N_{s}=28441$ evaluations, for the current case.

Next, we discuss the results of the abovementioned global sensitivity analysis for the model of Hakka et al. [17]. Figure 10 shows the sampled points and the path traced out during the sampling process in the two-dimensional space of the parameters corresponding to $A(272)$ and $A$ (253), which are the $A$ factors of Reaction 272 and Reaction 253, respectively. Figure 10(a) has been limited to the first 500 sampled points for clarity. As shown in Fig. 10(a), the first 500 
sample points for this particular two-dimensional parameter space were sampled in a regular and uniform fashion. The uniformity of the sampling within the stated region of uncertainty is further illustrated by means of a histogram for all the $N_{s}=28441$ sample points shown in Fig. 10(b).

The multiple evaluations, with all 32 parameters varied simultaneously, resulted in 32 scatter plots of the type shown in Figs. 11(a) and 11(b) for variations in the rate constants within the uncertainty limits. Reaction 253 and Reaction 272 in the model of Hakka et al. [17] showed a clear trend with respect to the variation of the respective parameter, and have therefore been chosen for the representative plots. It can be seen in Fig. 11 that increasing the pre-exponential factor for Reaction 253 leads to an increase in ignition delay, while decreasing that of Reaction 272 has the same effect. It is important to recall that all the $32 k_{i}$ 's were being simultaneously varied. To emphasize this point, we present a three-dimensional scatter plot with the axes corresponding to the $A$ factors for Reactions 253, 271, and 272, as shown in Fig. 12. The size of the superimposed bubbles in Fig. 12 scales with the magnitude of the ignition delay times. In addition, Fig. 12 visually confirms that the three-dimensional sub-space corresponding to these reactions has been adequately sampled by the search curve.

The influence of the variable $k_{i}$ (i.e. $A_{i}$ ) on the computed output (ignition delay time) in this set of evaluations can be characterized by a sensitivity index, as described in [64] and implemented in [65]. The normalized global sensitivity index for the model of Hakka et al. [17] is shown in Fig. 13. The results indicate that Reaction 253 and Reaction 272 are by far the most important/sensitive ones, consistent with the results for the scatter plots. Therefore, there is now a strong case for suggesting an adjustment in the rate constants for these two reactions to improve the match between the current experimental data and the computed results obtained from the model of Hakka et al. [17]. 
Since the original model under-predicts the experimental results, as a reasonable starting point, a computational experiment was done by adjusting the rate constants for these two reactions to their assumed limits of uncertainty so as to effect an increase in ignition delay time. Specifically, the rate constant for Reaction 253 was increased by multiplying a factor of $10^{+0.5}$ and the rate constant for Reaction 272 was reduced by multiplying a factor of $10^{-0.5}$. The results of such an adjustment on the ignition delay times are compared to the ignition delay results for the original model. The histograms in Figs. 14(a) and 14(b) are the global sensitivity results using the original and modified models, respectively, and also show the comparison with the relevant statistics. This attempt at reconciling the experimental and computed results seems to have a beneficial effect on the model predictions for the low-to-intermediate temperature regime as shown in Figs. 15(a)-15(c). For all the three conditions, ( $\phi=0.25, P_{C}=75$ bar), ( $\phi=0.5, P_{C}=30$ bar $),\left(\phi=1.0, P_{C}=15\right.$ bar $)$, shown in Fig. 15 , the modified model with the aforementioned adjustments to the two rate constants demonstrates a very good agreement with the experimental data. A similar comparison over different sets of equivalence ratio and compressed pressure conditions within the experimental temperature range also suggests an improvement, as shown in Fig. 16.

Of particular interest is the discrepancy between the experimental data and the simulated results shown in Fig. 16(b) for conditions corresponding to a compressed pressure of $P_{C}=30$ bar and an equivalence ratio of $\phi=1.0$ (filled triangles for experiments and dotted black line for simulations using the original model). It is found that the computed values begin to diverge significantly from the experimental results as one progresses to the lower temperatures, to the right of Fig. 16(b). This trend is unique to this set of conditions and is not observed for any other conditions shown in Figs. 15 and 16. The reason for this unexpectedly large deviation becomes 
clear when one takes a close look at the ignition delay response surface and the location of the experimental data points in relation to that, as discussed next.

The constant-volume, adiabatic ignition delay response surface as a function of pressure and temperature is shown in Fig. 17(a) for the original model of Hakka et al. [17]. It can be seen from Fig. 17(a) that the model begins predicting the onset of a NTC regime, approximately midway between the 30 bar experimental data, shown in relation to the computed ignition delay response surface, while the experimental data is a monotonic function of temperature. The appearance of the NTC trough in the computed results is responsible for the sharp deviation between the computed and experimental results. Figure 17(b) shows the response surface for the modified model, with the experimental data being located atop it. A comparison of Figs. 17(a) and 17(b) shows that the two adjustments to the original model have been able to reduce the discrepancy between experimental and computed results, not only by a simple translation of the response surface, but also by a shift in the nature and location of the NTC region. It is because of this shift in the location of the NTC trough that the modified model predicts the experimental data much better for a compressed pressure of 30 bar. Note that the 15 bar experimental results lie in the relatively high temperature region of the response surface where the better agreement is mainly due to a simple increase in the predicted ignition delay times (positive vertical shift of the response surface).

Furthermore, a comparison of the computed results obtained by the original and modified models in Fig. 17(a) and 17(b) indicates that the response in the high temperature region ( $>1000 \mathrm{~K}$ ) has been minimally affected due to the modification. We further verify this observation by using both the original and modified models to replicate the results for shock tube ignition delay reported in the study of Hakka et al. [17], as shown in Figs. 18(a) and 18(b). 
Figure 18 demonstrates that the ignition delay predictions under high temperature conditions are essentially identical for both the original and the modified models, at varying equivalence ratios. Thus, the attempted modification seems to have improved the low temperature predictions of the current experiments while maintain its previously demonstrated predictive capability under high temperature conditions.

Having identified the rate constant for the $\mathrm{H}$ atom abstraction by $\mathrm{HO}_{2}$ from the $\alpha$-site of methyl butanoate (Reaction 272) in the mechanism of Hakka et al. [17] as key to predicting ignition delay times, it is logical to compare the rates for the same reaction across the other mechanisms as well. The rates for $\mathrm{HO}_{2}+$ methyl butanoate in the model of Liu et al. [5] were generated by analogies to rate rules from the experimental [67] and theoretical [68] studies. In the mechanism of Dooley et al. [12], the rates for the hydrogen abstraction reaction involving the fuel and $\mathrm{HO}_{2}$ species were based on the experimental and modeling study by Orme et al. [69]. The mechanism of Hakka et al. [17] evaluated the rates for hydrogen abstraction by $\mathrm{HO}_{2}$ using a Evans-Polanyi type correlation from Dean and Bozzelli [70]. Moreover, the $\mathrm{H}$ abstraction rate parameters in the mechanism of Dievart et al. [59] were adopted from a previous modeling effort by Herbinet et al. [71]. A comparison of this particular rate constant as included in the mechanisms of Fisher et al.[57], Gaïl et al. [58], Dooley et al. [12], Hakka et al. [17], Dievart et al. [59], and Liu et al. [5] is shown in Fig. 19. It also includes the modified rate constant used in this work to obtain a better match with the current experiments as shown in Figs. 15 and 16. It can be seen from Fig. 19 that the rate constant for the aforementioned reaction has the highest value over the entire temperature range in the kinetic scheme of Liu et al. [5]. This is in keeping with the trend in Fig. 5 where this mechanism is found to exhibit the shortest ignition delay time. Also, note that the rate constant in the mechanism of Hakka et al. [17] has the lowest value under 
low temperature conditions. Furthermore, based on Fig. 19, the rate constant for this reaction is found to vary by a factor of 12 on the high temperature side and a factor of 20 on the low temperature side amongst the different literature kinetic schemes. We were able to obtain a reasonable match by adjusting (reducing) the rate constant for Reaction 272 in the kinetic scheme of Hakka et al. [17] by only multiplying a factor of $10^{-0.5}$. The radical resulting from methyl butanoate with $\mathrm{H}$ abstracted at the $\alpha$ site further participates in a reaction with molecular oxygen to form a methyl crotonate isomer and $\mathrm{HO}_{2}$. This reaction (Reaction 253) exhibits a positive sensitivity to ignition delay time and increasing its rate constant leads to a longer ignition delay time. The rate constant for Reaction 253 was increased by a factor of $10^{+0.5}$ when calculating the ignition delay times using the modified mechanism of Hakka et al. [17]. In view of the fact that there is a wide disagreement between the various chemical kinetic models in prediction of the low-to-intermediate temperature ignition delay times, and that the model of Hakka et al. [17] currently best predicts the current data, further experimental and computational studies on the aforementioned two reactions (Reaction 272 and Reaction 253) in the model of Hakka et al. [17] are required. In addition, recognizing that sensitivity analysis does not introduce any new reactions and that low temperature chemistry is more complex and not well understood, parallel efforts in identifying missing pathways that are important under low-tointermediate temperatures are warranted.

\section{Conclusions}

Using a rapid compression machine, ignition delay times for methyl butanoate have been obtained over a wide range of thermodynamic conditions relevant to compression ignition engines. New high-pressure and low-to-intermediate-temperature data are under realistic fuel 
loadings and cover from fuel lean to stoichiometric conditions. These new ignition delay data sets complement the literature data and provide additional targets for model validation. In addition, the experimental data have been compared to results from computations using several chemical kinetic models reported in the literature. These literature models were found to severely under-predict the current experimental results. Detailed sensitivity analyses, both local and global, were conducted to identify the cause of this mismatch between experimental and computed ignition delay times, and suggestions were made for improvement. The impact of the low-temperature oxidation kinetics on the ignition delay times has been identified and demonstrated by studying the model response to parameter variation. Furthermore, the computational findings indicate a need for further investigation into the rate constants associated with the $\mathrm{HO}_{2}$ chemistry in the methyl butanoate kinetic model, similar to Reaction 253 and Reaction 272 in the model of Hakka et al. [17].

\section{Acknowledgments}

This material is based upon work supported as part of the Combustion Energy Frontier Research Center, an Energy Frontier Research Center funded by the U.S. Department of Energy, Office of Science, Office of Basic Energy Sciences under Award Number DE-SC0001198.

\section{Supplementary Data}

Supplementary data for volume-time histories used in the simulations are available for online access with the journal article. 


\section{List of Figures}

Fig. 1: Ignition delay times as a function of compressed temperature $\left(T_{C}\right)$, with compressed pressure $\left(P_{C}\right)$ as a parameter for (a) $\phi=0.25$, (b) $\phi=0.5$, and (c) $\phi=1.0$.

Fig. 2: Experimental pressure traces corresponding to an equivalence ratio of $\phi=0.25$ at varying compressed temperatures and for compressed pressures of (a) $P_{C}=15$ bar, (b) $P_{C}=30$ bar, (c) $P_{C}=45$ bar, and (d) $P_{C}=75$ bar.

Fig. 3: The influence of equivalence ratio on ignition delay time at a given compressed pressure of $P_{C}=30$ bar and a compressed temperature of $T_{C} \approx 910 \mathrm{~K}$.

Fig. 4: Ignition delay correlation for the current experimental data sets.

Fig. 5: Comparative experimental and simulated pressure traces at one fixed condition $(\phi=0.5$, $P_{C}=35$ bar, $T_{C}=904 \mathrm{~K}$ ) to illustrate the difference between experiment and simulation and indicate the variability in simulated values obtained using different chemical kinetic schemes.

Fig. 6: Arrhenius plots comparing experimental data to simulated values using various chemical kinetic models for (a) $\phi=0.25, P_{C}=75$ bar, (b) $\phi=0.5, P_{C}=30 \mathrm{bar}$, and (c) $\phi=1.0$, $P_{C}=15$ bar.

Fig. 7: Results of a brute force sensitivity analysis for the ignition delay times obtained using the chemical kinetic model of Hakka et al. (2010) for (a) fuel lean and (b) stoichiometric conditions.

Fig. 8: Selected simulated pressure traces obtained as a result of the brute force sensitivity analysis using the chemical kinetic model of Hakka et al. (2010) for (a) fuel lean and (b) stoichiometric conditions.

Fig. 9: Fuel consumption pathways for an initial condition of $T=904 \mathrm{~K}$ and $P=30$ bar, related to the brute force sensitivity shown in Figs. 7(a) and 8(a), at time instant corresponding to a 5 Kelvin rise in temperature. 
Fig. 10: (a) Plot showing the first 500 sampling points for the pre-exponential factors for Reaction 253 and Reaction 272. The lines represent the path followed during the sampling process. (b) Histogram for all the sample points showing the uniformity of the sampling within the stated uncertainty range.

Fig. 11: Scatter plots showing the variation of ignition delay times as the pre-exponential factors corresponding to (a) Reaction 253, $A(253)$ and (b) Reaction 272, $A(272)$ are varied over the parameter space. Note that all pre-exponential factors for other reactions having an absolute sensitivity greater than $2.5 \%$ are also varied simultaneously.

Fig. 12: Bubble plot showing the variation of ignition delay times as the pre-exponential factors $A(253), A(271)$, and $A(272)$, corresponding to Reaction 253, Reaction 271, and Reaction 272 , respectively, are varied over the parameter space. The size of the bubbles scales with the magnitude of the ignition delay times. Note that all pre-exponential factors for other reactions having an absolute sensitivity greater than $2.5 \%$ are also varied simultaneously.

Fig. 13: Normalized global sensitivity index results for the ignition delay times obtained using the chemical kinetic model of Hakka et al. (2010).

Fig. 14: Histogram of global sensitivity results on ignition delay times obtained using (a) the original model of Hakka et al. (2010) and (b) the modified model with $A(253)$ and $A(272)$ being adjusted.

Fig. 15: Comparison between the computational results, obtained using the original (dotted lines) and modified (solid lines) models of Hakka et al. (2010) under low-to-intermediate temperature conditions, and the current experimental RCM data for (a) $\phi=0.25, P_{C}=75$ bar, (b) $\phi=0.5$, $P_{C}=30$ bar, and (c) $\phi=1.0, P_{C}=15$ bar.

Fig. 16: Comparison between the computational results, obtained using the original (dotted lines) 
and modified (solid lines) models of Hakka et al. (2010) under low-to-intermediate temperature conditions, and the current experimental RCM data for (a) $P_{C}=15$ bar and (b) $P_{C}=30$ bar with equivalence ratio as a parameter.

Fig. 17: Ignition delay response surfaces for (a) the original model of Hakka et al. (2010) and (b) the modified model. The current experimental data points are indicated as filled circles. The response surfaces have been obtained for constant-volume, adiabatic conditions. The contours correspond to pressures of 10,15, 20, 25, 30, and 35 bar and for stoichiometric conditions.

Fig. 18: Comparison between the computational results, obtained using the original and modified models of Hakka et al. (2010) under high temperature conditions, and the experimental shock tube data of Hakka et al. [17] for (a) $\phi=0.25, P_{5} \approx 8.4 \mathrm{~atm}$ (b) $\phi=1.0, P_{5} \approx 8.4 \mathrm{~atm}$.

Fig. 19: Comparison of rate constants for $\mathrm{H}$ atom abstraction by $\mathrm{HO}_{2}$ on the $\alpha$ site of methyl butanoate from various chemical kinetic models. 


\section{Figure 1}

(a) Ignition Delay for Methyl Butanoate $(\phi=0.25$ )

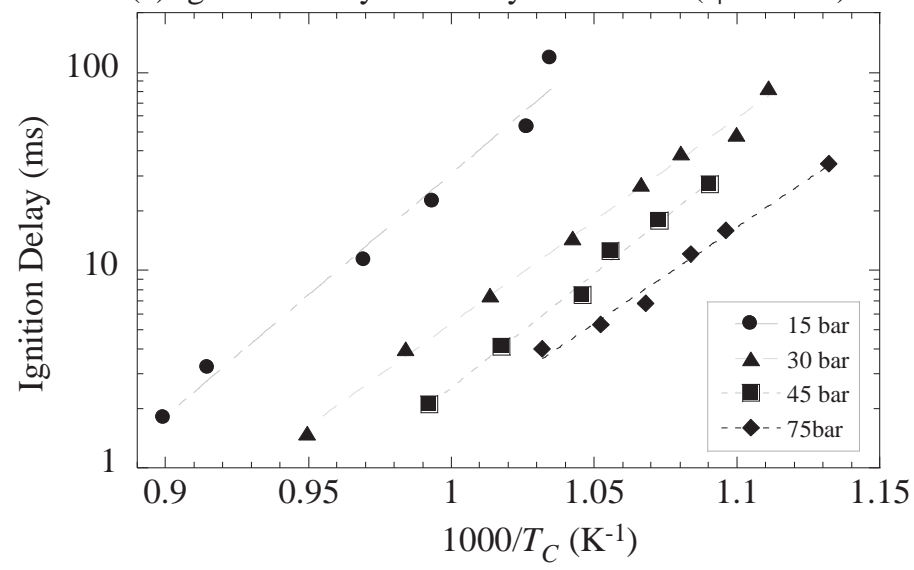

(b) Ignition Delay for Methyl Butanoate $(\phi=0.5)$

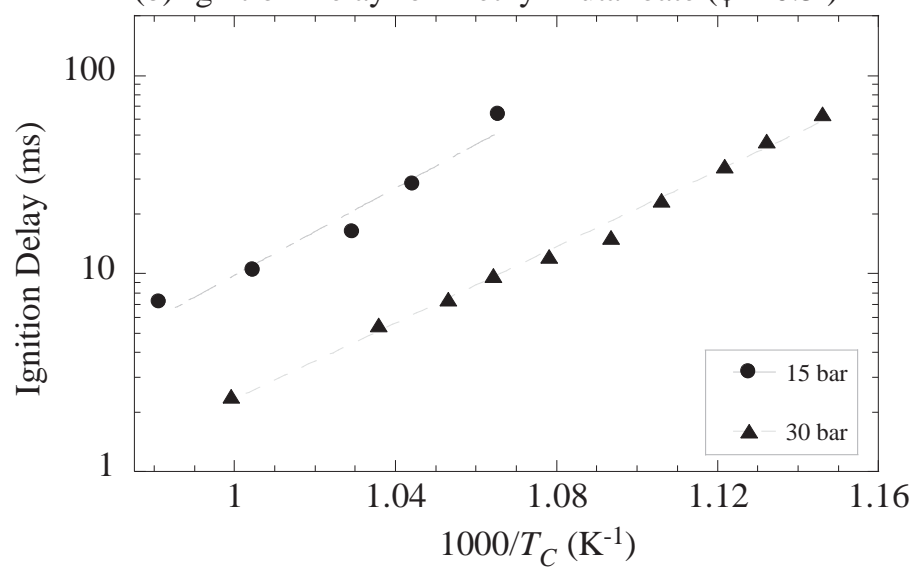

(c) Ignition Delay for Methyl Butanoate $(\phi=1.0)$

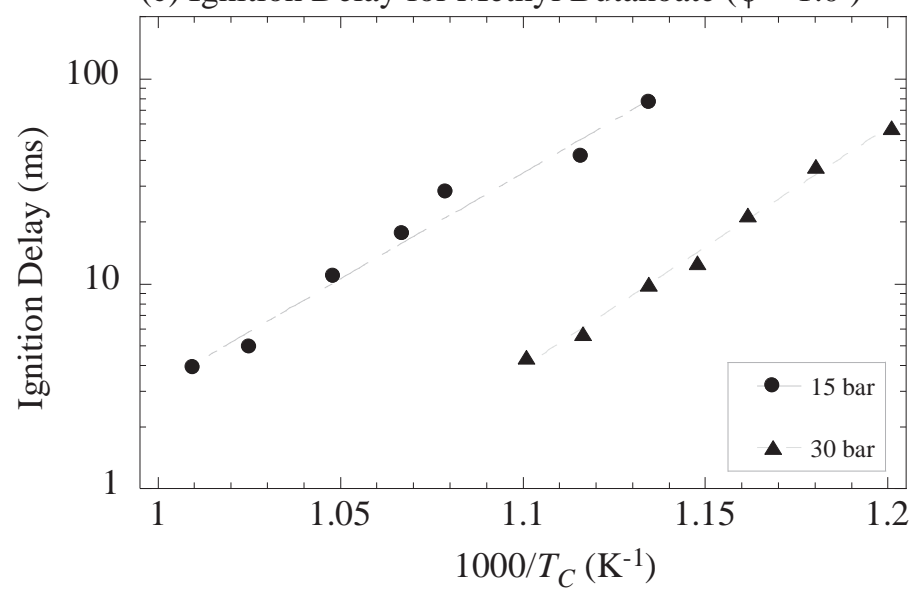




\section{Figure 2}
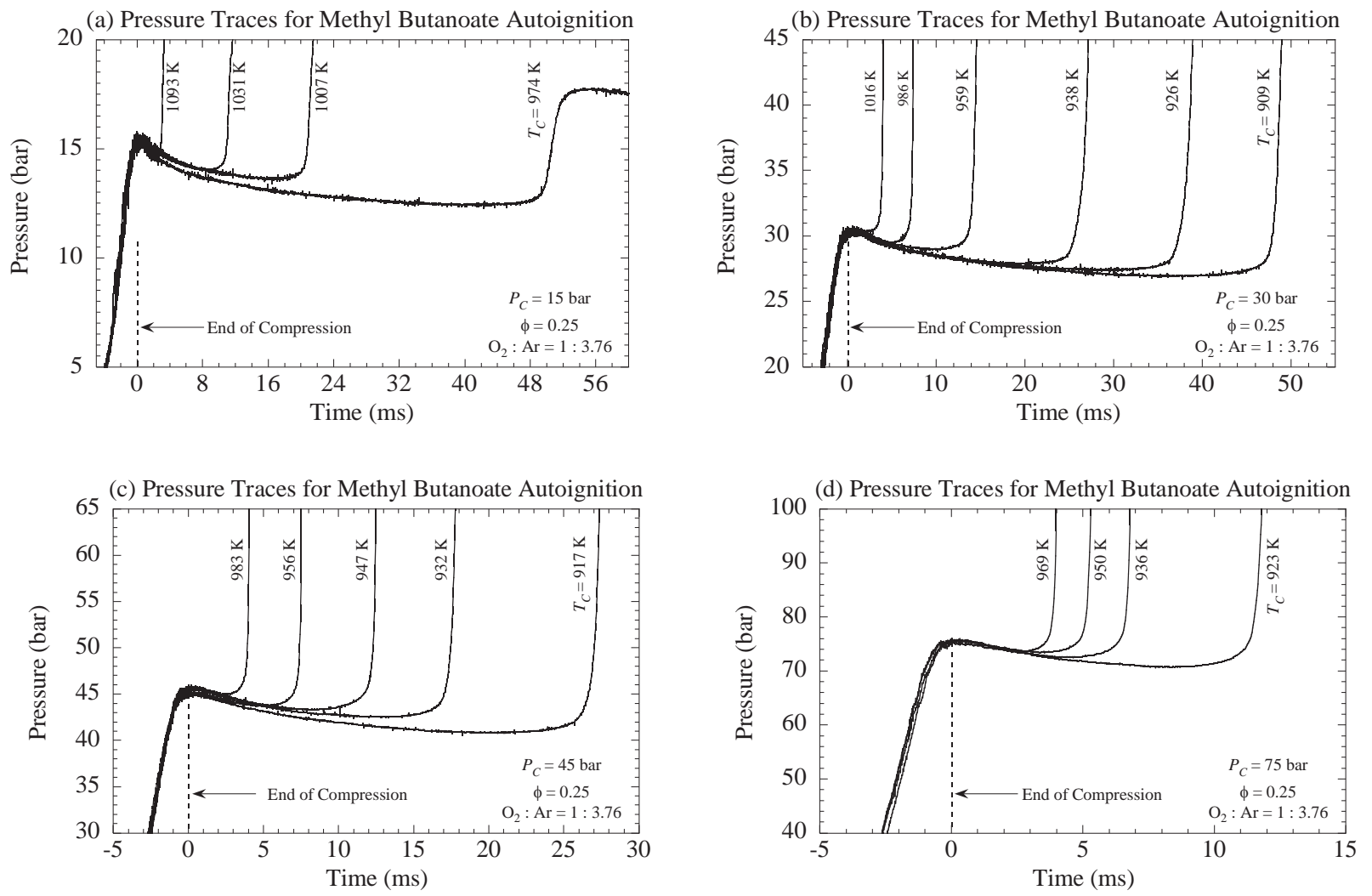
Figure 3

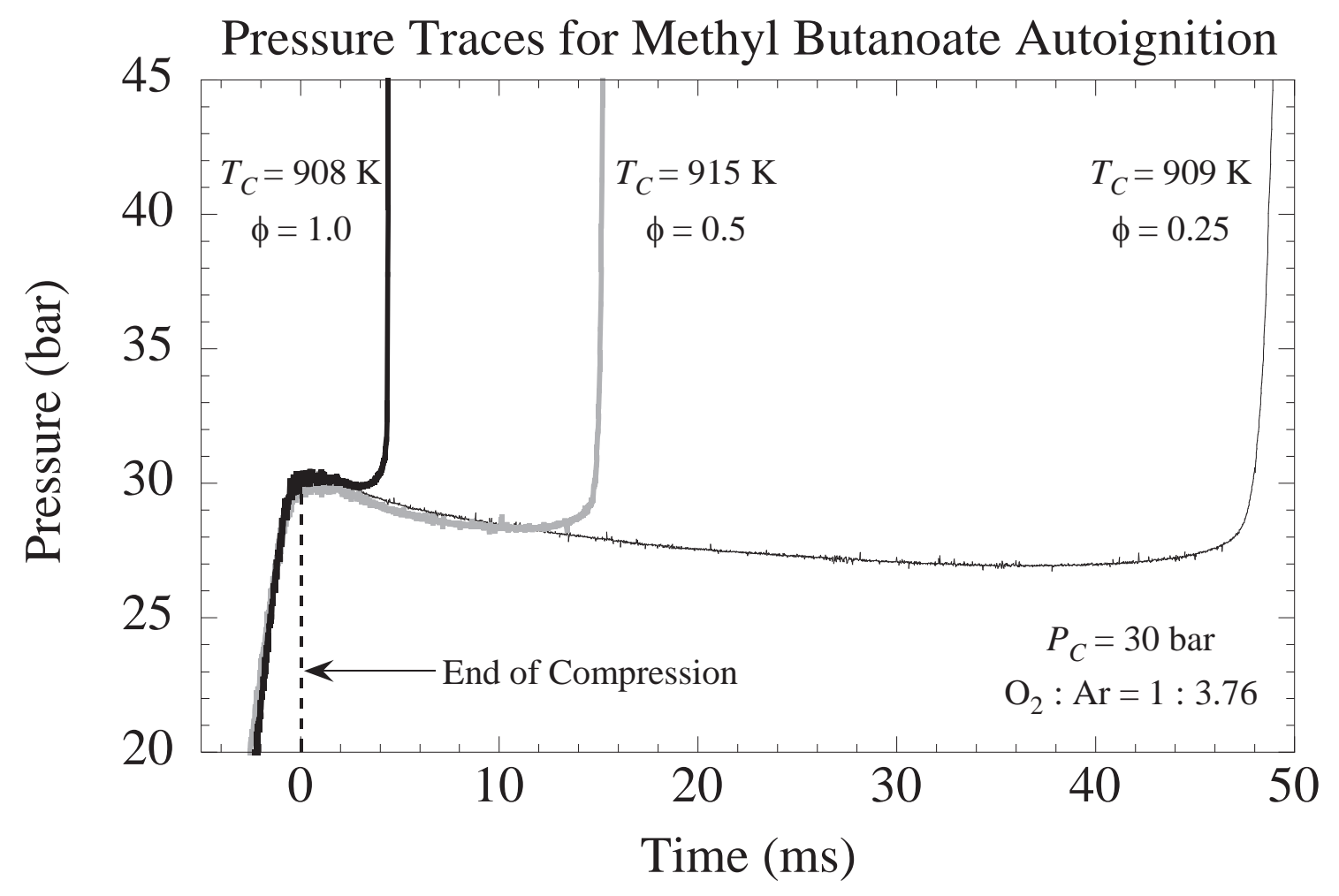


Figure 4

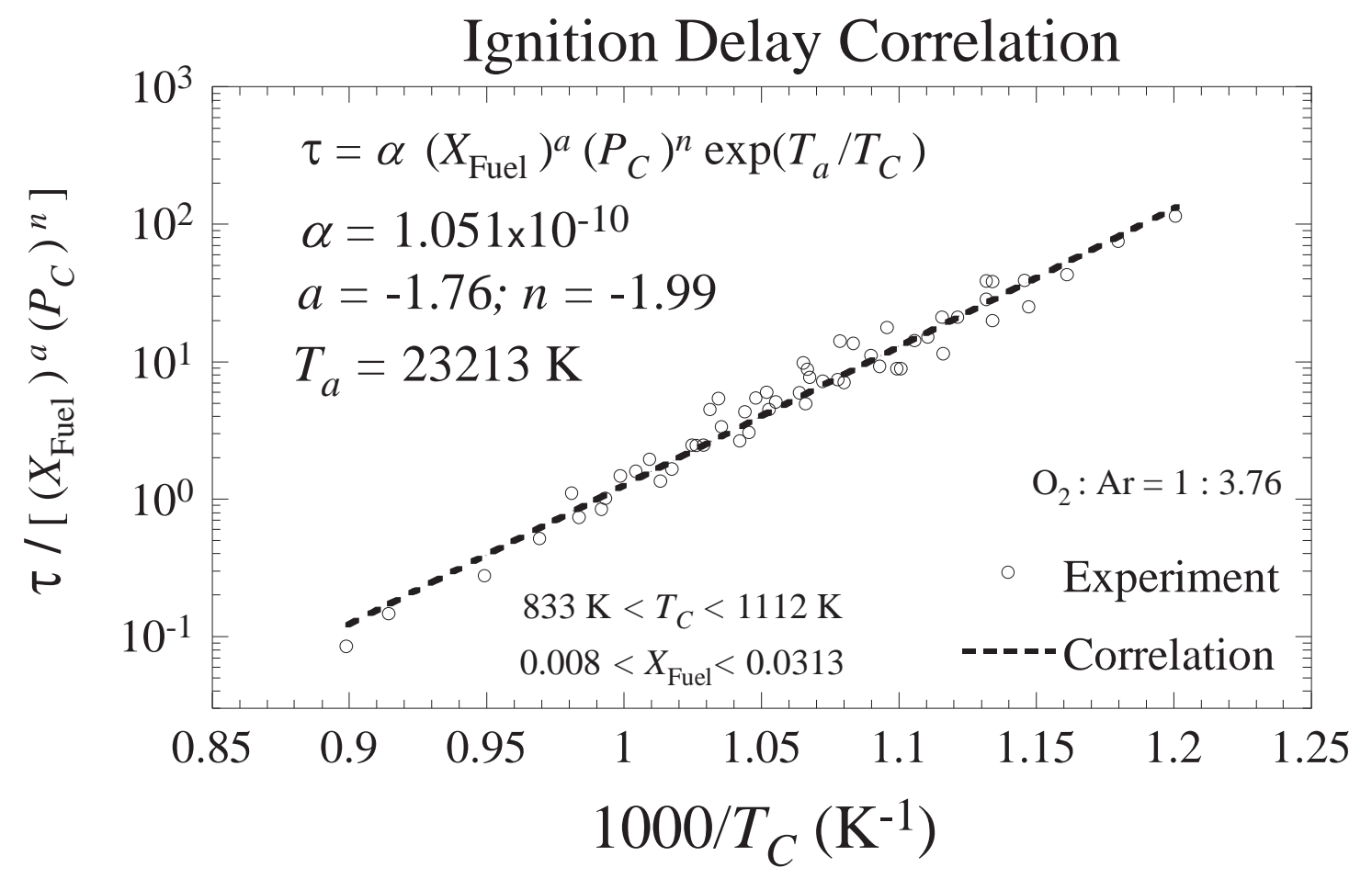


Figure 5

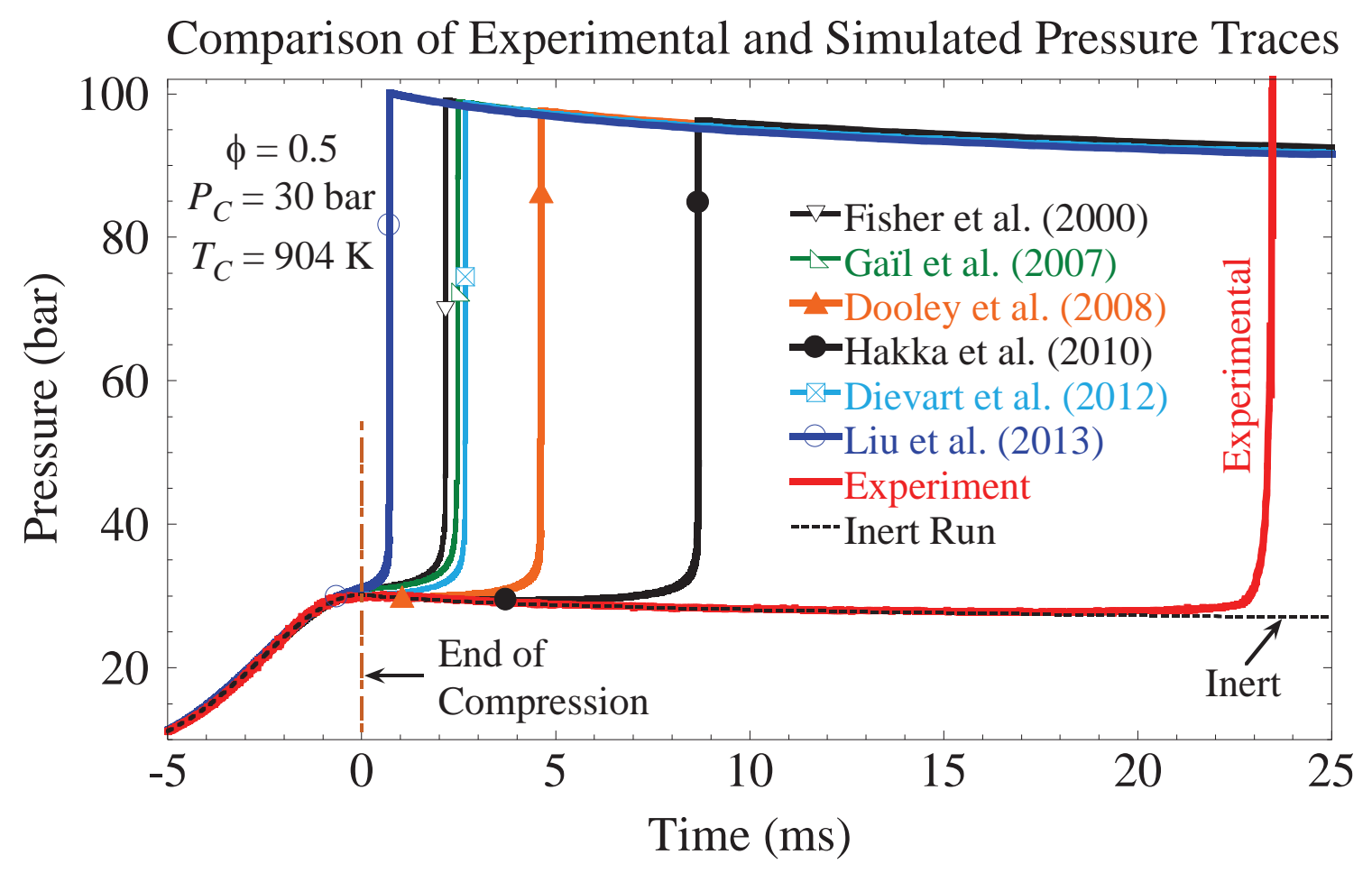




\section{Figure 6}

(a) Comparison of Experimental and Simulated Ignition Delays

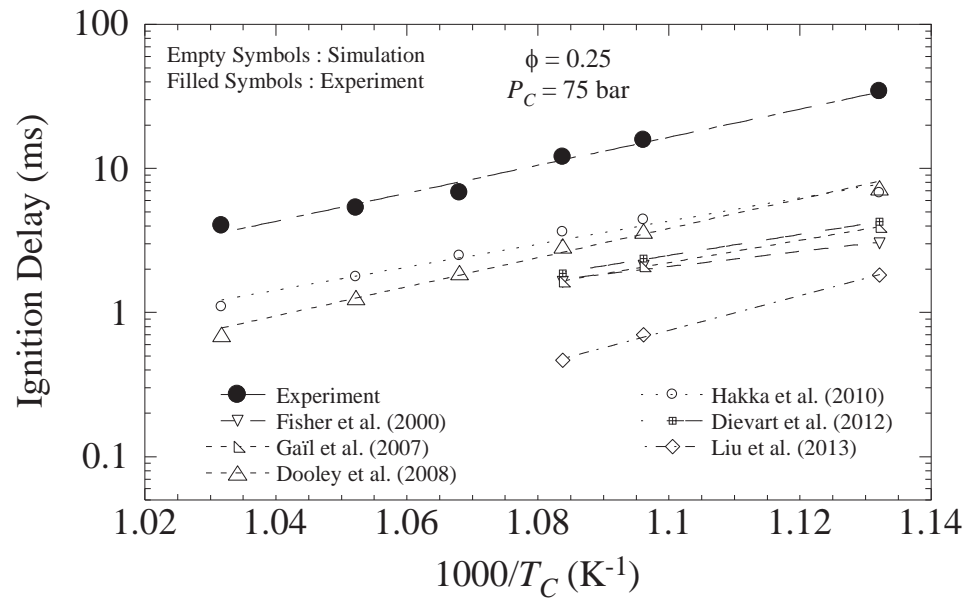

(b) Comparison of Experimental and Simulated Ignition Delays

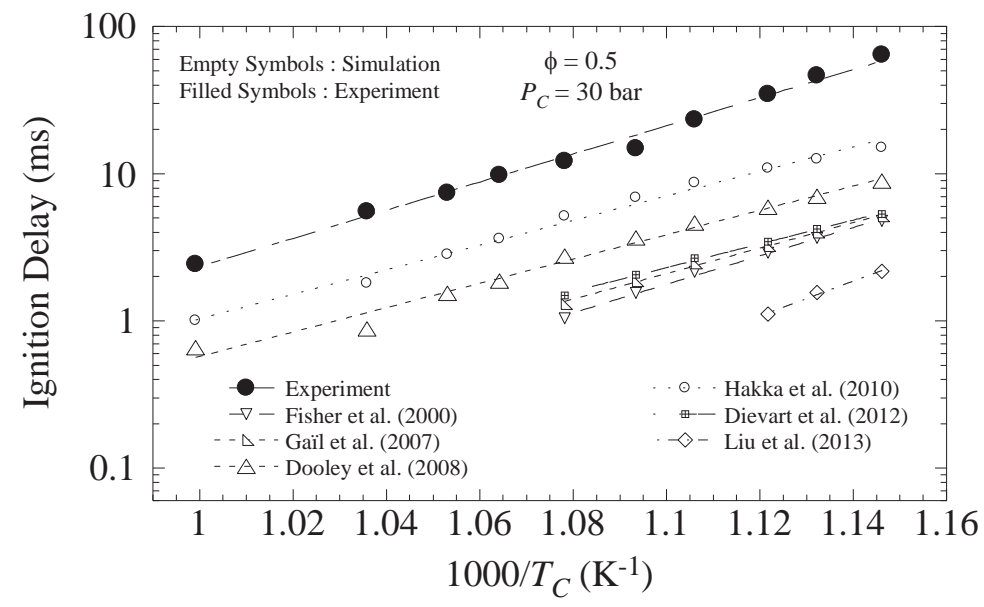

(c) Comparison of Experimental and Simulated Ignition Delays

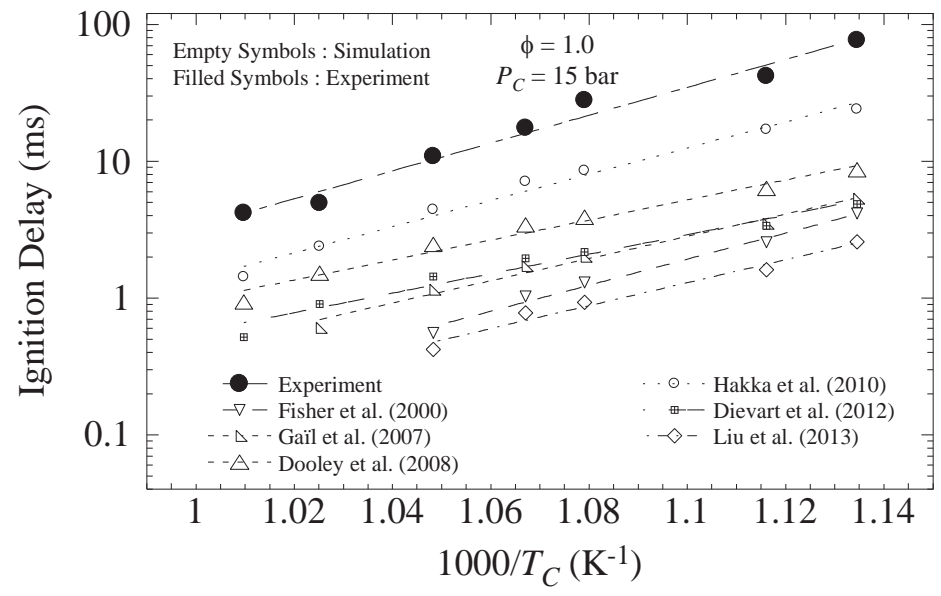


Figure 7

\section{(a) Effect of Doubling Rate Constants on Simulated Ignition Delay}

\begin{tabular}{|c|c|c|}
\hline \multicolumn{2}{|c|}{ 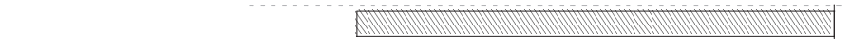 } & $\mathrm{C} 5 \mathrm{H} 10 \mathrm{O} 2 \mathrm{~S}-1+\mathrm{HO} 2=>\mathrm{H} 2 \mathrm{O} 2+\mathrm{R} 28 \mathrm{C} 5 \mathrm{H} 9 \mathrm{O} 2 \mathrm{~S}$ \\
\hline \multicolumn{2}{|c|}{ R36C5H904US=R51C5H904PS } & \\
\hline \multicolumn{2}{|c|}{$\mathrm{C} 5 \mathrm{H} 10 \mathrm{O} 2 \mathrm{~S}-1+\mathrm{HO} 2=>\mathrm{H} 2 \mathrm{O} 2+\mathrm{R} 27 \mathrm{C} 5 \mathrm{H} 9 \mathrm{O} 2 \mathrm{~S}$} & \\
\hline R36C5H904US=R49C5H904PS & mindind & \\
\hline $\mathrm{C} 5 \mathrm{H} 10 \mathrm{O} 2 \mathrm{~S}-1+\mathrm{OH}=>\mathrm{H} 2 \mathrm{O}+\mathrm{R} 26 \mathrm{C} 5 \mathrm{H} 9 \mathrm{O} 2 \mathrm{~S}$ & & \\
\hline $\mathrm{R} 27 \mathrm{C} 5 \mathrm{H} 9 \mathrm{O} 2 \mathrm{~S}+\mathrm{O} 2=\mathrm{R} 34 \mathrm{C} 5 \mathrm{H} 904 \mathrm{US}$ & Nintin & \\
\hline $\mathrm{C} 5 \mathrm{H} 10 \mathrm{O} 2 \mathrm{~S}-1+\mathrm{HO} 2=>\mathrm{H} 2 \mathrm{O} 2+\mathrm{R} 29 \mathrm{C} 5 \mathrm{H} 902 \mathrm{~S}$ & & $\phi=0.5$ \\
\hline R49C5H9O4PS+O2=R69C5H9O6UPS & Min & $P_{C}=30 \mathrm{bar}$ \\
\hline $\begin{array}{l}\text { R37C5H9O4US }=\text { R53C5H9O4PS } \\
\text { C5H10 }\end{array}$ & (n) & $T_{C}=904 \mathrm{~K}$ \\
\hline $\begin{array}{l}\text { C5H10O2S }-1+\mathrm{HO} 2=>\mathrm{H} 2 \mathrm{O} 2+\mathrm{R} 26 \mathrm{C} 5 \mathrm{H} 9 \mathrm{O} 2 \mathrm{~S} \\
\mathrm{C} 5 \mathrm{H} 10 \mathrm{O} 2 \mathrm{~S}-1+\mathrm{OH}=>\mathrm{H} 2 \mathrm{O}+\mathrm{R} 27 \mathrm{C} 5 \mathrm{H} 9 \mathrm{O} 2 \mathrm{~S}\end{array}$ & minis & Hakka et al. (2010) \\
\hline $\mathrm{R} 28 \mathrm{C} 5 \mathrm{H} 9 \mathrm{O} 2 \mathrm{~S}=>\mathrm{R} 4 \mathrm{CH} 3+\mathrm{C} 4 \mathrm{H} 6 \mathrm{O} 2 \mathrm{ZS}$ & initions & \\
\hline $\mathrm{R} 51 \mathrm{C} 5 \mathrm{H} 904 \mathrm{PS}=>\mathrm{OH}+\mathrm{C} 5 \mathrm{H} 803 \mathrm{ES} \# 5$ & & $\mathrm{~S}:$ Ester [-CO-O-CH3] \\
\hline $\mathrm{R} 48 \mathrm{C} 5 \mathrm{H} 904 \mathrm{PS}=>0 \mathrm{H}+\mathrm{C} 5 \mathrm{H} 803 \mathrm{ES} \#$ & & $\mathrm{U}:$ Peroxy [-O-O-] \\
\hline $\mathrm{R} 29 \mathrm{C} 5 \mathrm{H} 9 \mathrm{O} 2 \mathrm{~S}+\mathrm{O} 2=>\mathrm{C} 5 \mathrm{H} 8 \mathrm{O} 2 \mathrm{ZS}+\mathrm{HO} 2$ & & $\mathrm{P}:$ : Hydroperoxide $[-\mathrm{O}-\mathrm{O}-\mathrm{H}]$ \\
\hline $\mathrm{R} 49 \mathrm{C} 5 \mathrm{H} 904 \mathrm{PS}=>\mathrm{OH}+\mathrm{C} 5 \mathrm{H} 803 \mathrm{E} 3 \mathrm{~S}$ & & $\mathrm{E}:$ : Ether $[-\mathrm{O}-]$ \\
\hline $\mathrm{R} 26 \mathrm{C} 5 \mathrm{H} 9 \mathrm{O} 2 \mathrm{~S}+\mathrm{O} 2=>\mathrm{C} 5 \mathrm{H} 802 \mathrm{ZS}+\mathrm{HO} 2$ & & $\mathrm{R}$ : Radical $\ldots$ \\
\hline $\mathrm{C} 5 \mathrm{H} 10 \mathrm{O} 2 \mathrm{~S}-1+\mathrm{OH}=>\mathrm{H} 2 \mathrm{O}+\mathrm{R} 28 \mathrm{C} 5 \mathrm{H} 9 \mathrm{O} 2 \mathrm{~S}$ & & $\mathrm{Z}$ : Unsaturation $[-\mathrm{C}=\mathrm{C}-\mathrm{-}]$ \\
\hline $\begin{array}{l}\mathrm{R} 28 \mathrm{C} 5 \mathrm{H} 9 \mathrm{O} 2 \mathrm{~S}+\mathrm{O} 2=>\mathrm{C} 5 \mathrm{H} 8 \mathrm{O} 2 \mathrm{ZS}+\mathrm{HO} 2 \\
\mathrm{R} 2\end{array}$ & & \\
\hline 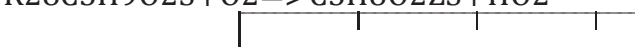 & 1 & . \\
\hline-50 & 0 & 50 \\
\hline
\end{tabular}

\section{(b) Effect of Doubling Rate Constants on Simulated Ignition Delay}


Figure 8

(a) Effect of Doubling $A$ Factors, One at a Time, on Simulated Ignition Delay

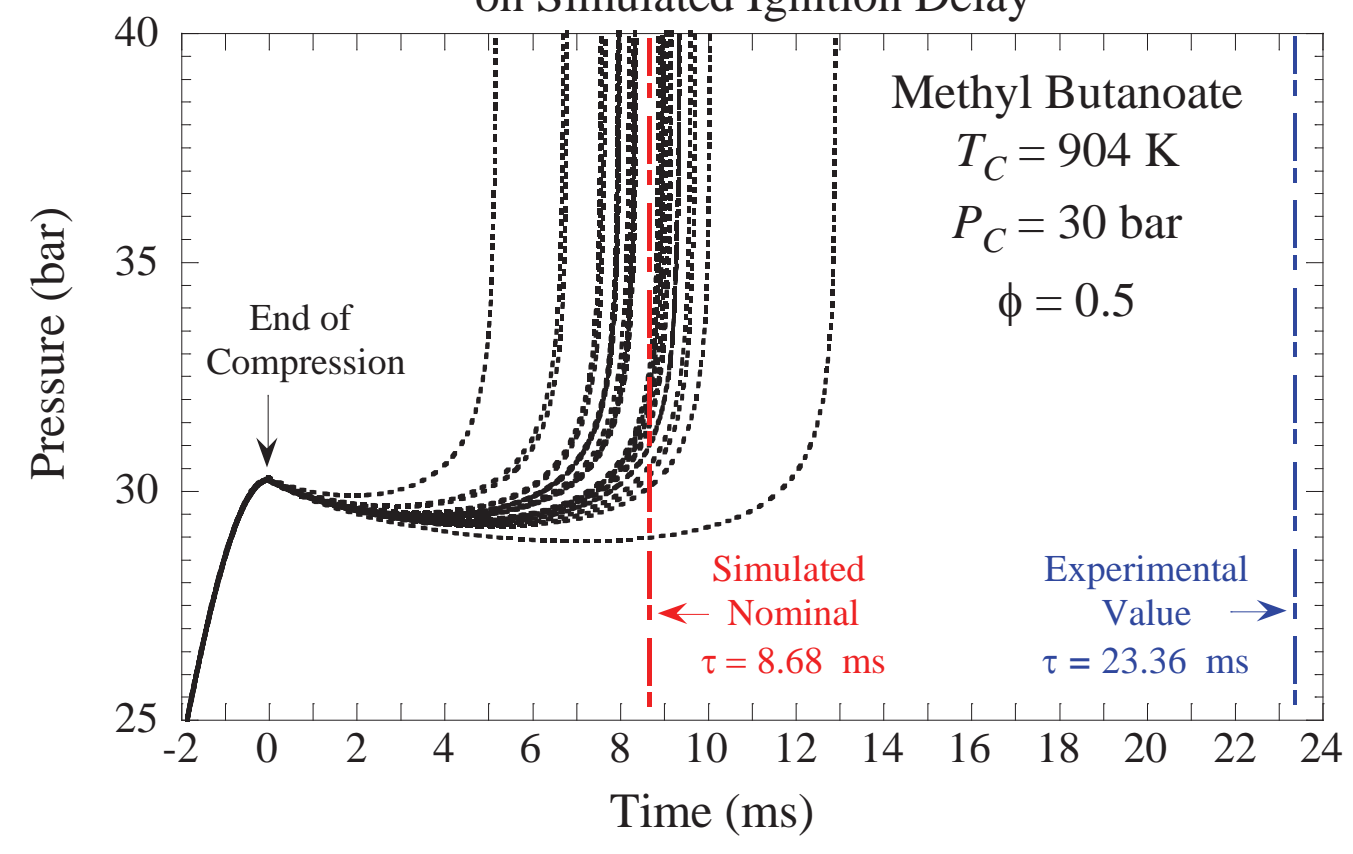

(b) Effect of Doubling A Factors, One at a Time,

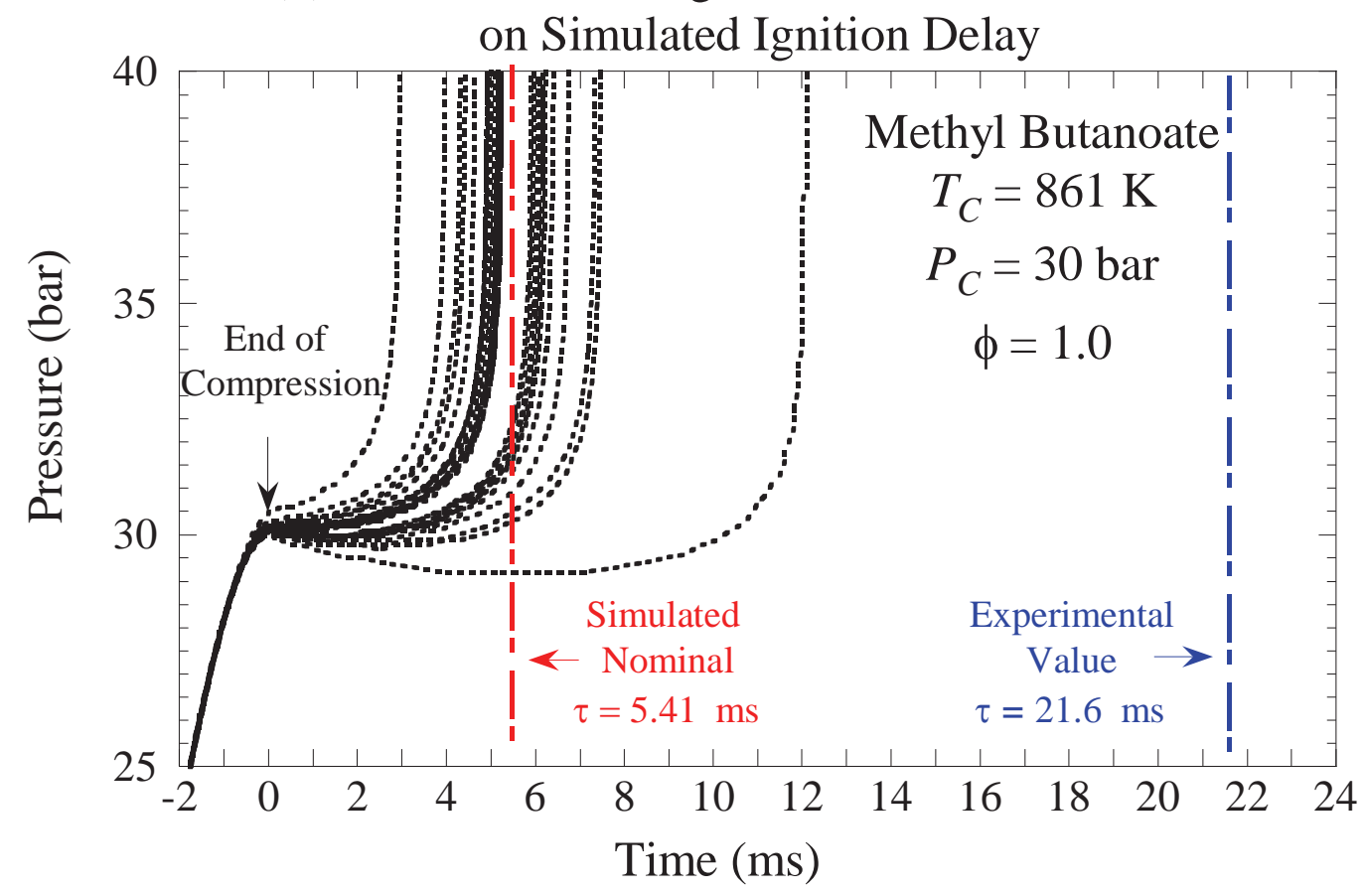


Figure 9

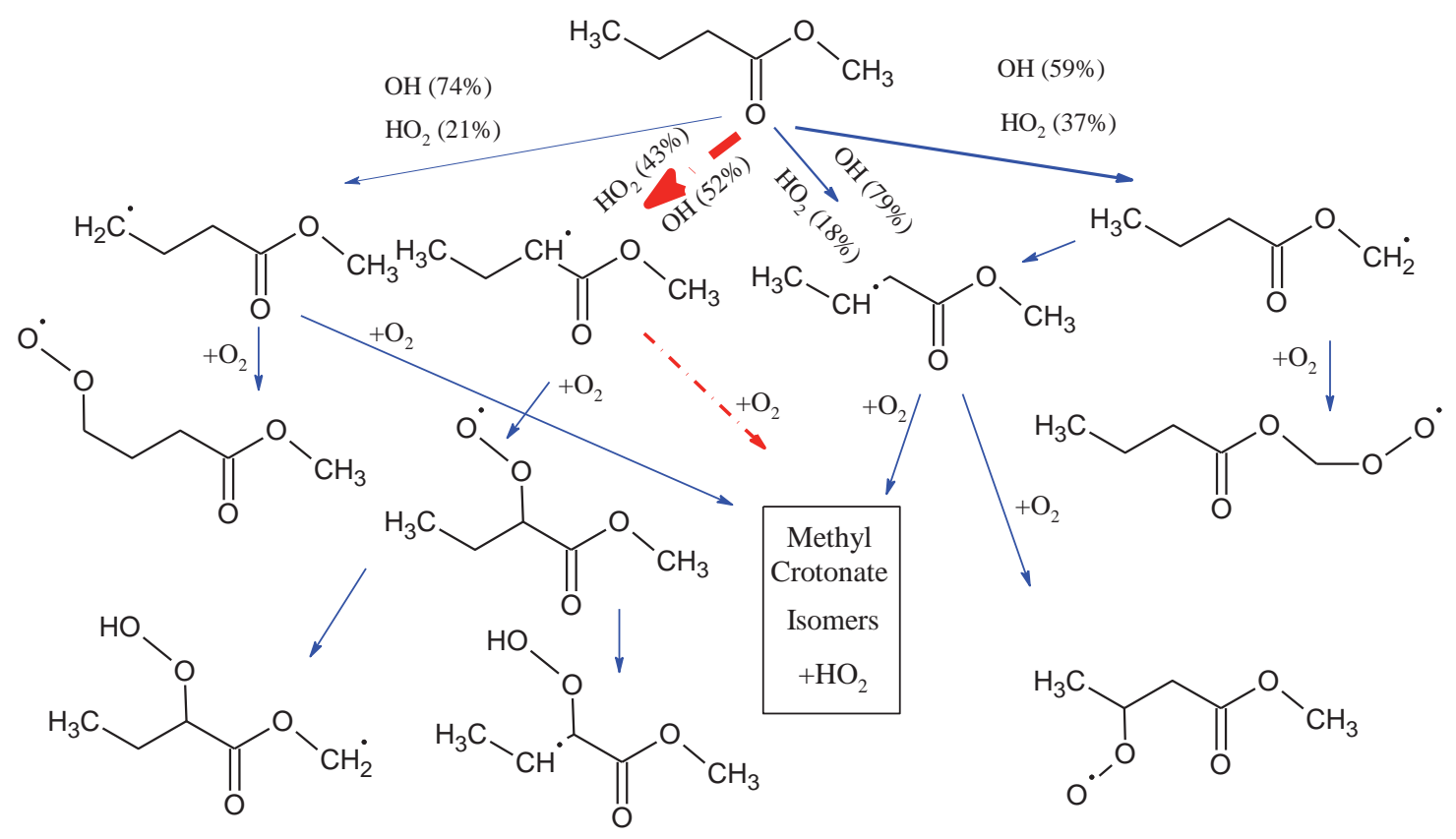


Figure 10

(a) First 500 Sampling Points with Path Traced Out

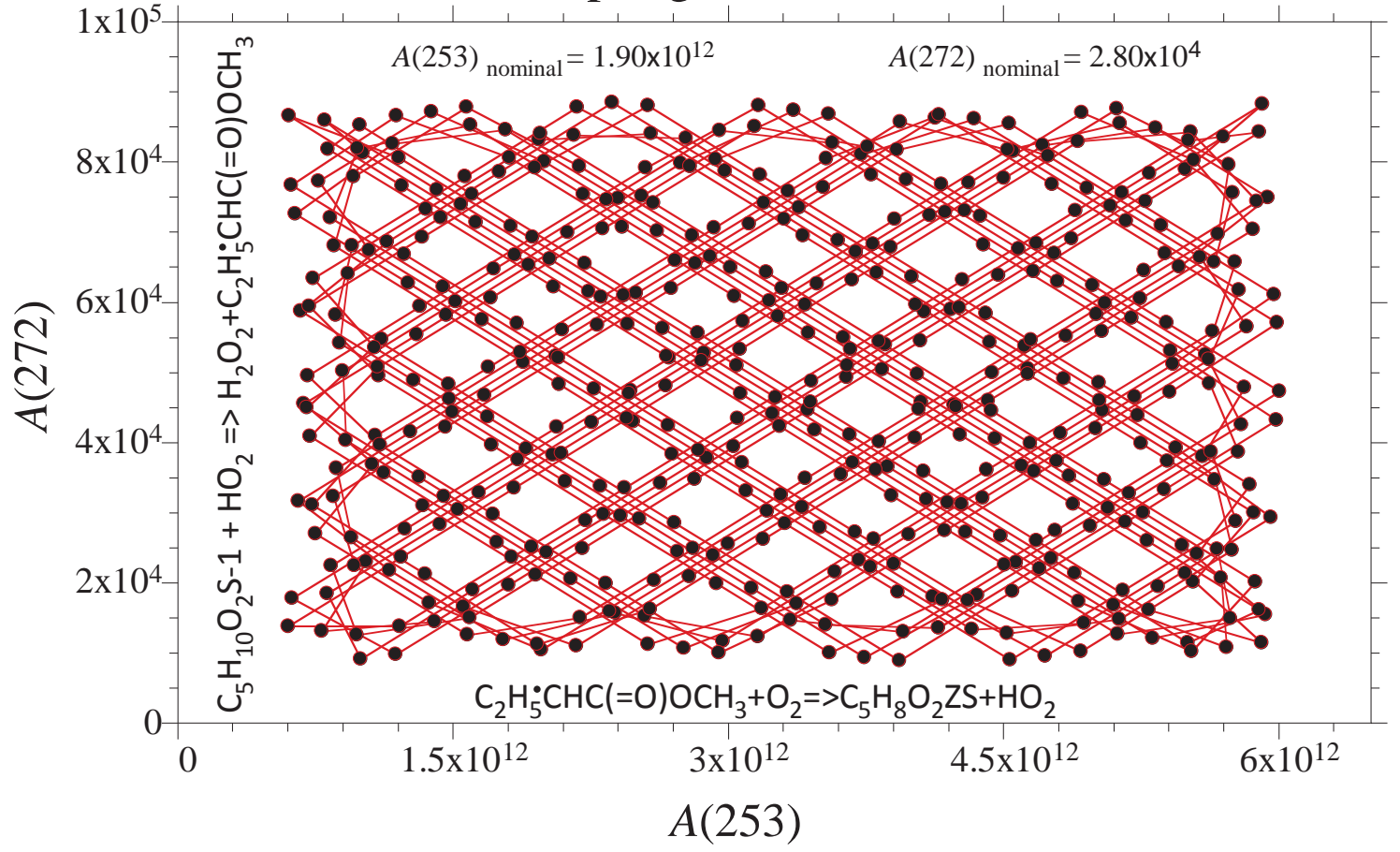

(b) Histogram of Sampled Points for A(272)

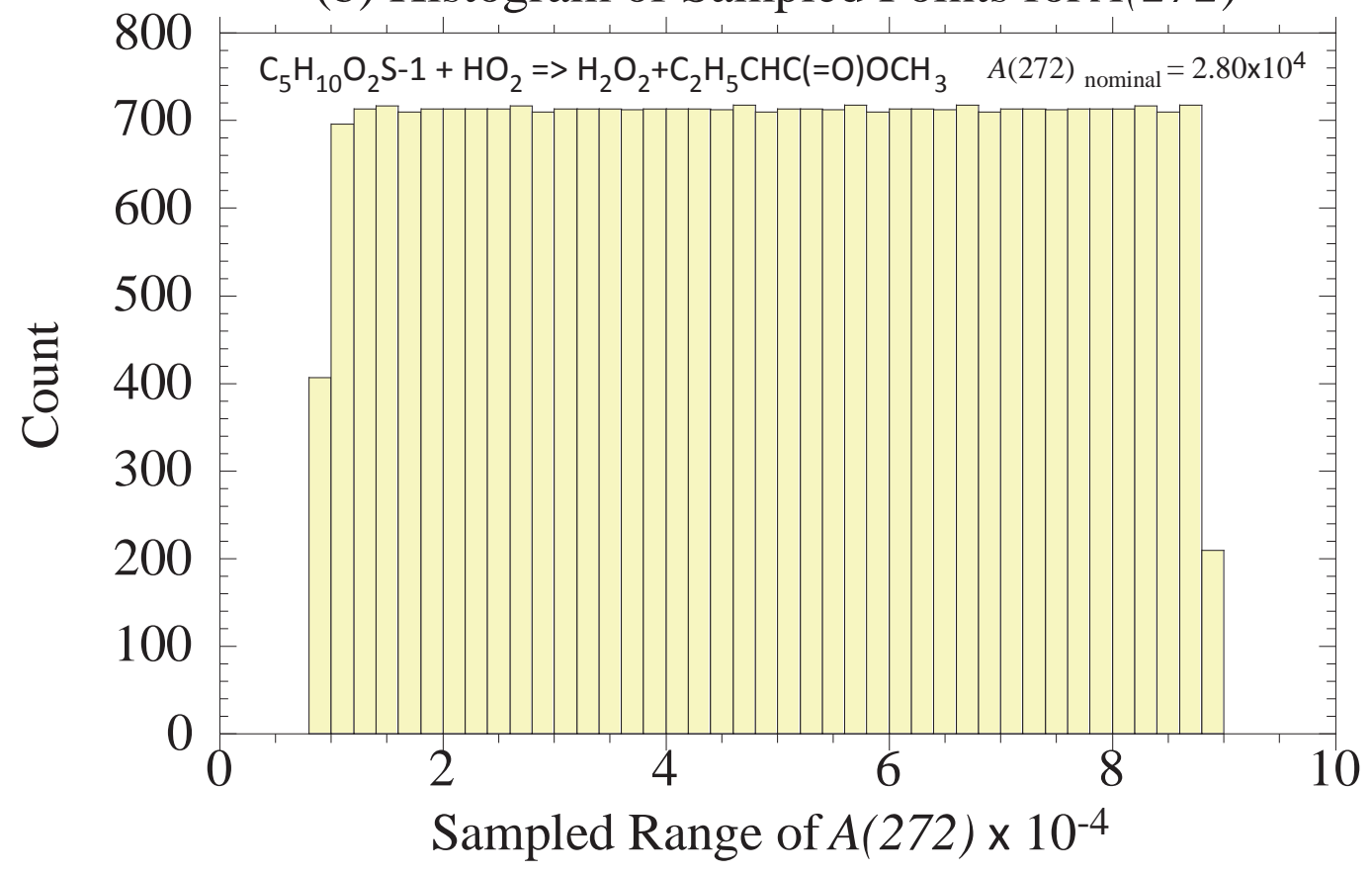


Figure 11

(a) Scatter Plot of Ignition Delay for Simultaneous Variation of A Factors

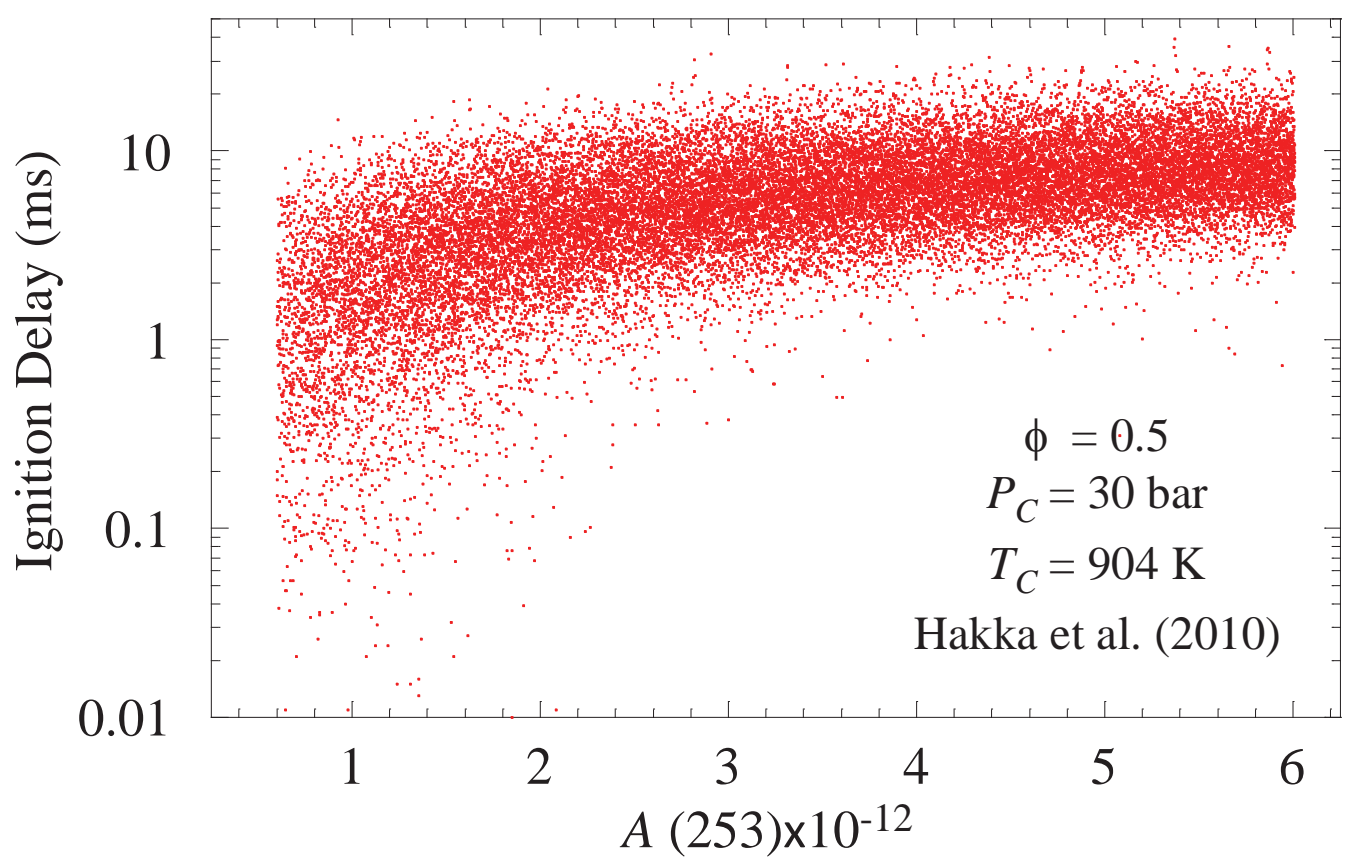

(b) Scatter Plot of Ignition Delay for Simultaneous Variation of A Factors

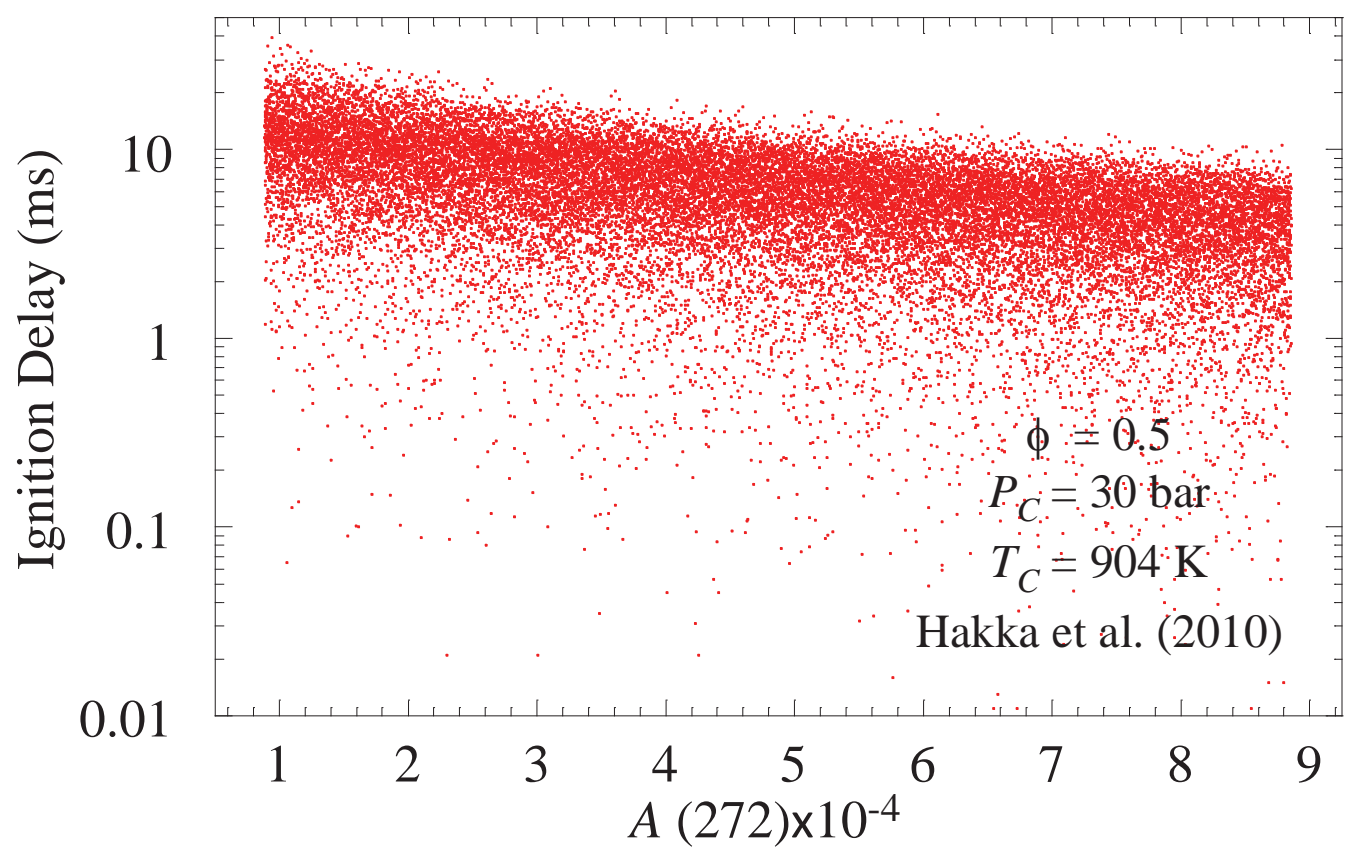


Figure 12

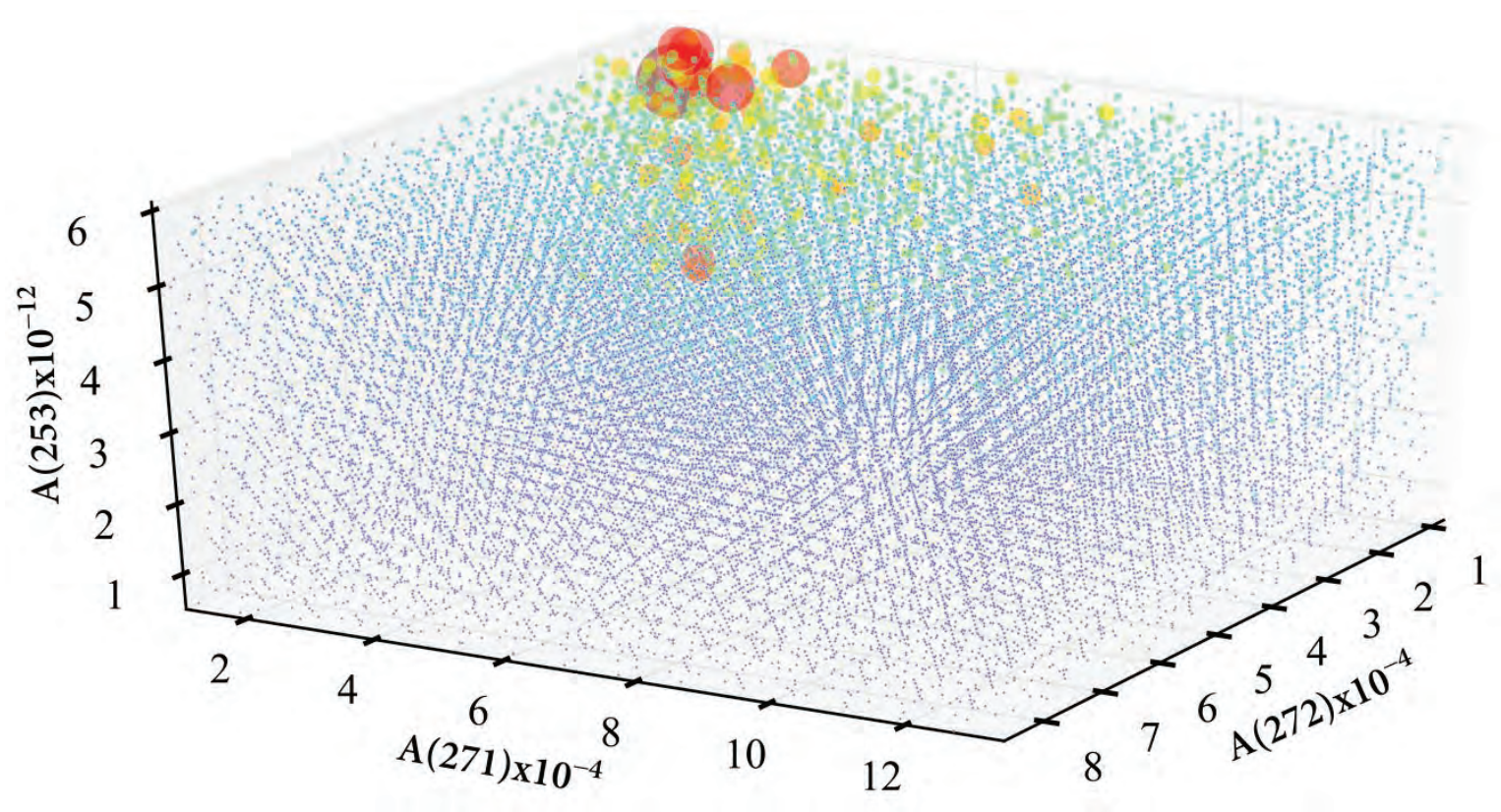


Figure 13

\section{Normalized Global Sensitivity Index}

\begin{tabular}{|c|c|c|}
\hline & $\mathrm{R} 28 \mathrm{C} 5 \mathrm{H} 9 \mathrm{O} 2 \mathrm{~S}+\mathrm{O} 2=>\mathrm{C} 5 \mathrm{H} 8 \mathrm{O} 2 \mathrm{ZS}+\mathrm{HO} 2$ & \\
\hline & $\mathrm{C} 5 \mathrm{H} 10 \mathrm{O} 2 \mathrm{~S}-1+\mathrm{HO} 2=>\mathrm{H} 2 \mathrm{O} 2+\mathrm{R} 28 \mathrm{C} 5 \mathrm{H} 9 \mathrm{O} 2 \mathrm{~S}$ & \\
\hline & $\mathrm{C} 5 \mathrm{H} 10 \mathrm{O} 2 \mathrm{~S}-1+\mathrm{HO} 2=>\mathrm{H} 2 \mathrm{O} 2+\mathrm{R} 27 \mathrm{C} 5 \mathrm{H} 9 \mathrm{O} 2 \mathrm{~S}$ & \\
\hline & R36C5H9O4US=R51C5H904PS & $\phi=0.5$ \\
\hline & $\mathrm{C} 5 \mathrm{H} 10 \mathrm{O} 2 \mathrm{~S}-1+\mathrm{OH}=>\mathrm{H} 2 \mathrm{O}+\mathrm{R} 28 \mathrm{C} 5 \mathrm{H} 9 \mathrm{O} 2 \mathrm{~S}$ & $\begin{array}{l}P_{C}=30 \mathrm{bar}^{-} \\
T_{G}=904 \mathrm{~K}\end{array}$ \\
\hline & $\mathrm{R} 29 \mathrm{C} 5 \mathrm{H} 9 \mathrm{O} 2 \mathrm{~S}+\mathrm{O} 2=>\mathrm{C} 5 \mathrm{H} 8 \mathrm{O} 2 \mathrm{ZS}+\mathrm{HO} 2$ & Hakka et al. (2010) \\
\hline & $\mathrm{R} 26 \mathrm{C} 5 \mathrm{H} 9 \mathrm{O} 2 \mathrm{~S}+\mathrm{O} 2=>\mathrm{C} 5 \mathrm{H} 8 \mathrm{O} 2 \mathrm{ZS}+\mathrm{HO} 2$ & S : Ester [-CO-O-CH3] \\
\hline & $\mathrm{R} 27 \mathrm{C} 5 \mathrm{H} 9 \mathrm{O} 2 \mathrm{~S}+\mathrm{O} 2=\mathrm{R} 34 \mathrm{C} 5 \mathrm{H} 9 \mathrm{O} 4 \mathrm{US}$ & $\begin{array}{l}\mathrm{U}: \text { Peroxy [-O-O-] } \\
\mathrm{P}: \text { Hydroperoxide [-O-O-H] }\end{array}$ \\
\hline \begin{tabular}{|l} 
\\
\end{tabular} & R36C5H9O4US=R49C5H9O4PS & $\begin{array}{l}\text { E : Ether }[-\mathrm{O}-] \\
\mathrm{R}: \text { Radical }\end{array}$ \\
\hline$\square$ & R49C5H904PS+O2=R69C5H9O6UPS & $\mathrm{Z}:$ Unsaturation $[-\mathrm{C}=\mathrm{C}-]$ \\
\hline 0 & $\begin{array}{lll}0.2 & 0.4 & 0.6\end{array}$ & .8 \\
\hline
\end{tabular}


Figure 14
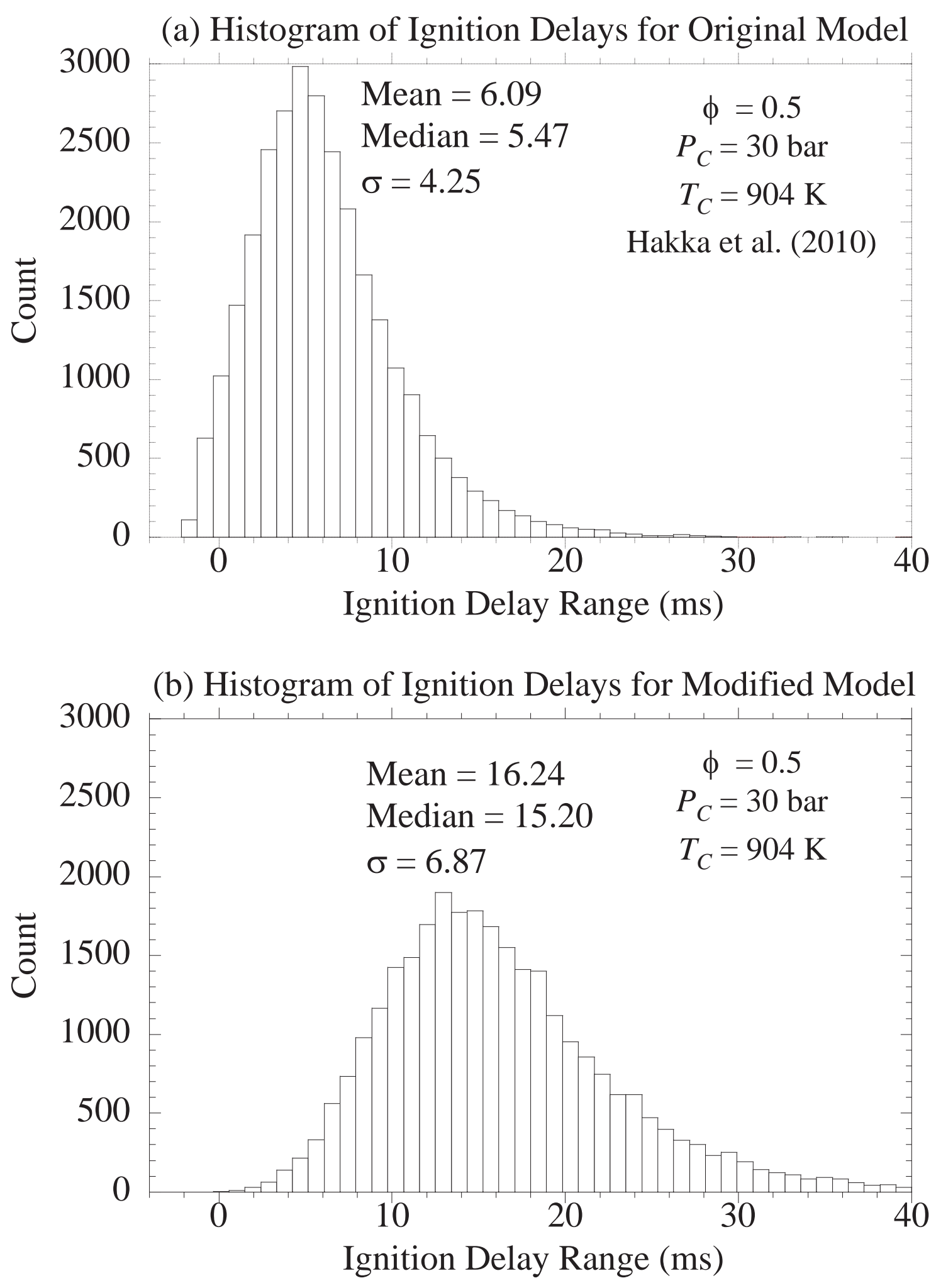
Figure 15

(a) Comparison of Experimental and Simulated Ignition Delays

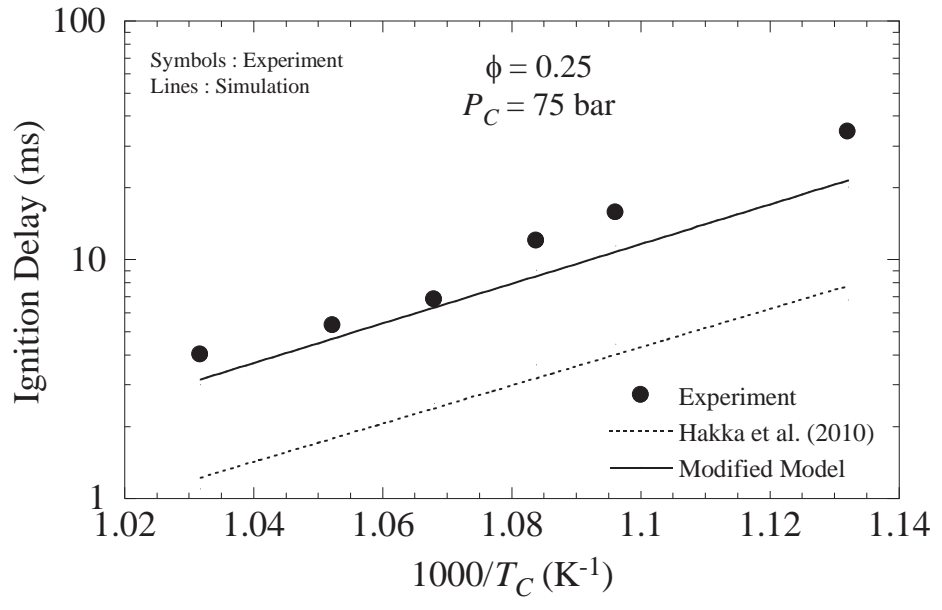

(b) Comparison of Experimental and Simulated Ignition Delays

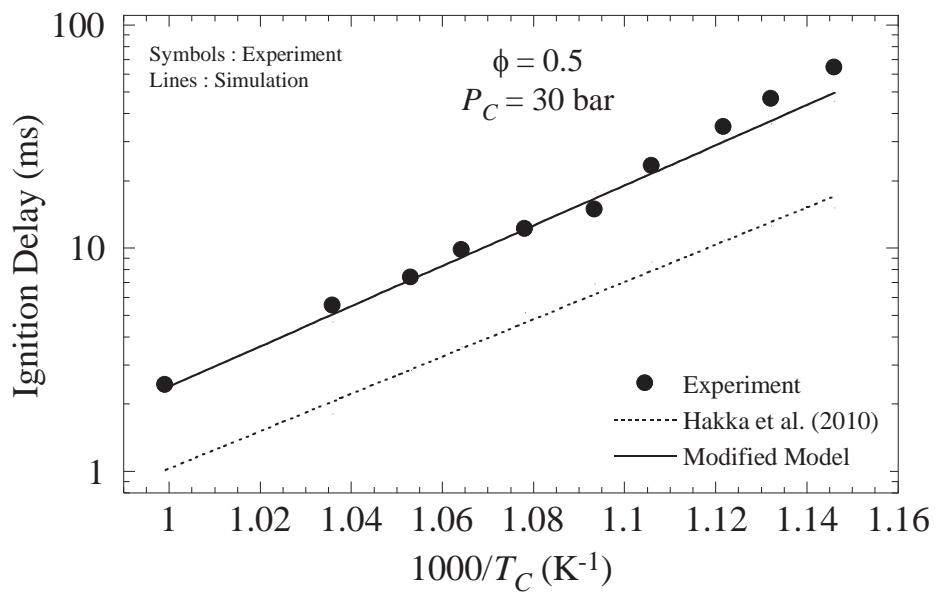

(c) Comparison of Experimental and Simulated Ignition Delays

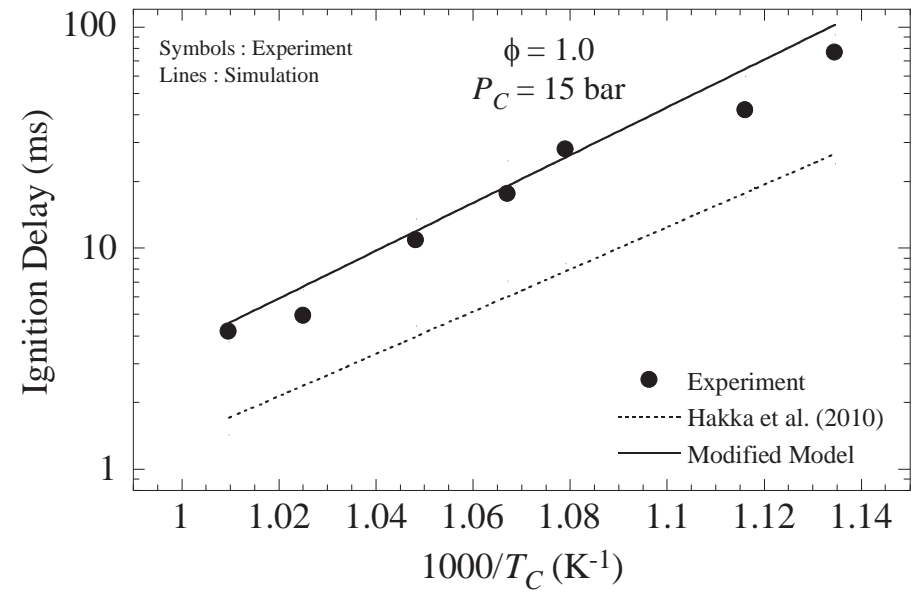


Figure 16

(a) Comparison of Experimental and Simulated Ignition Delays

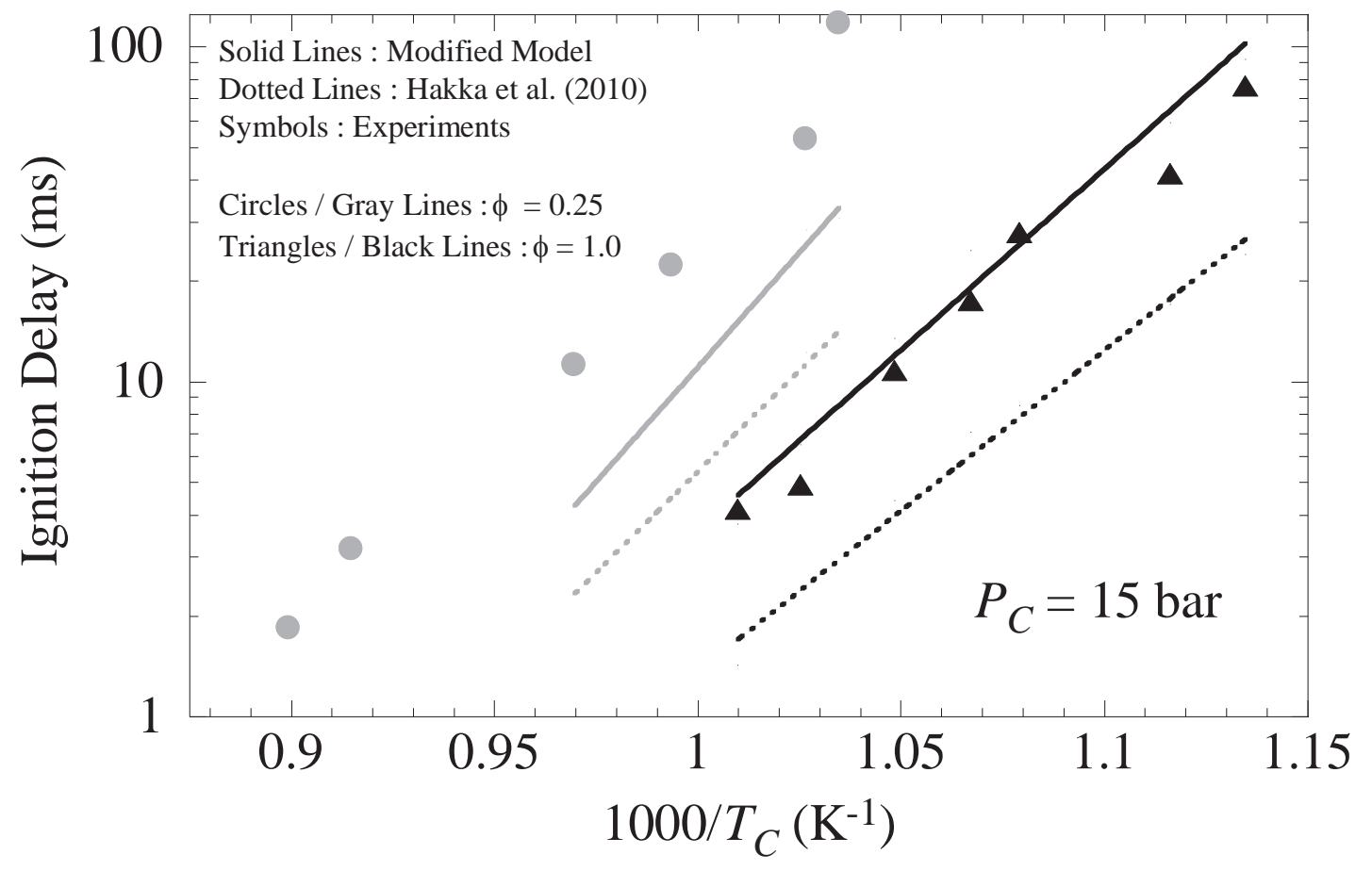

(b) Comparison of Experimental and Simulated Ignition Delays

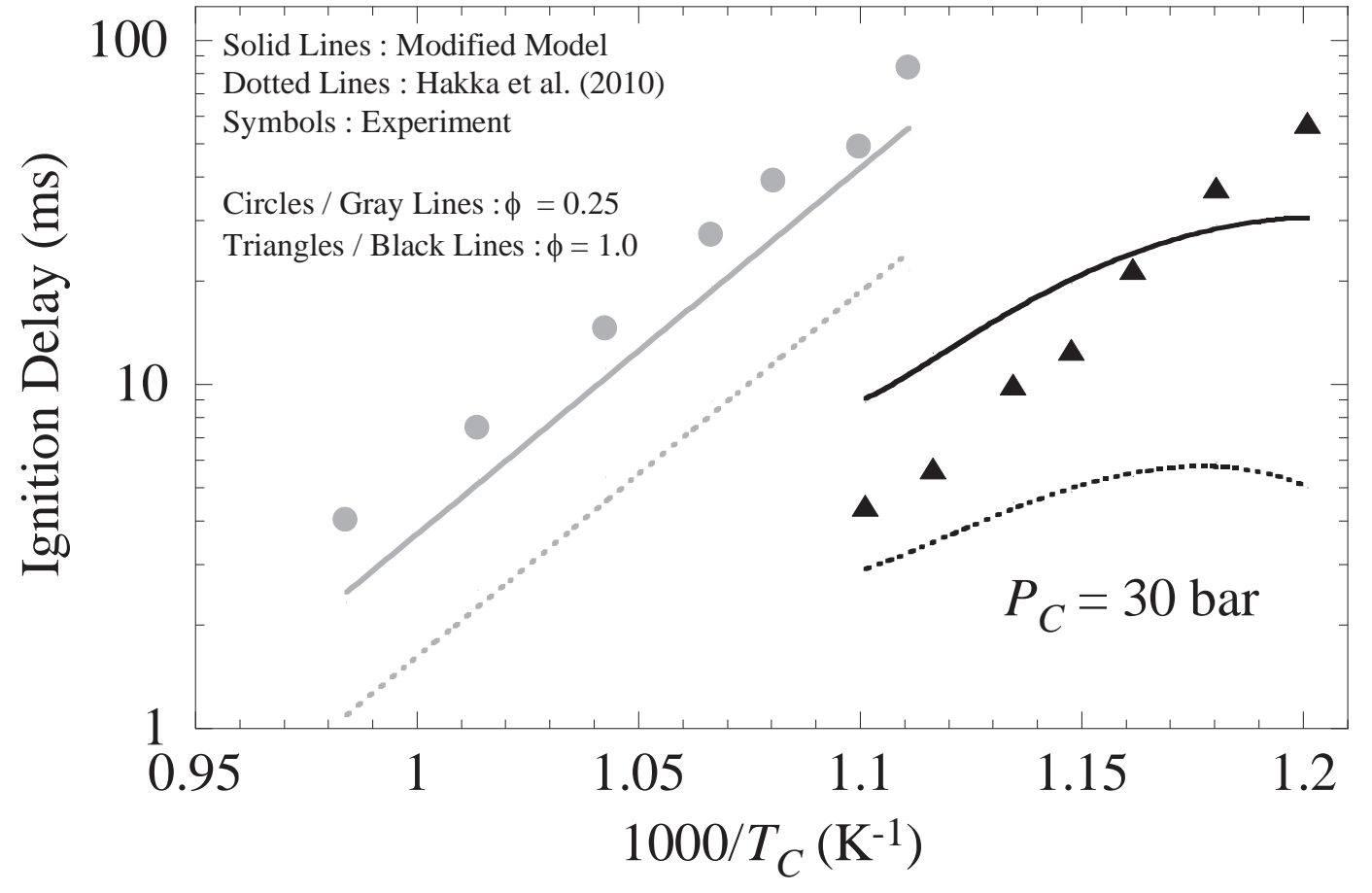


Figure 17
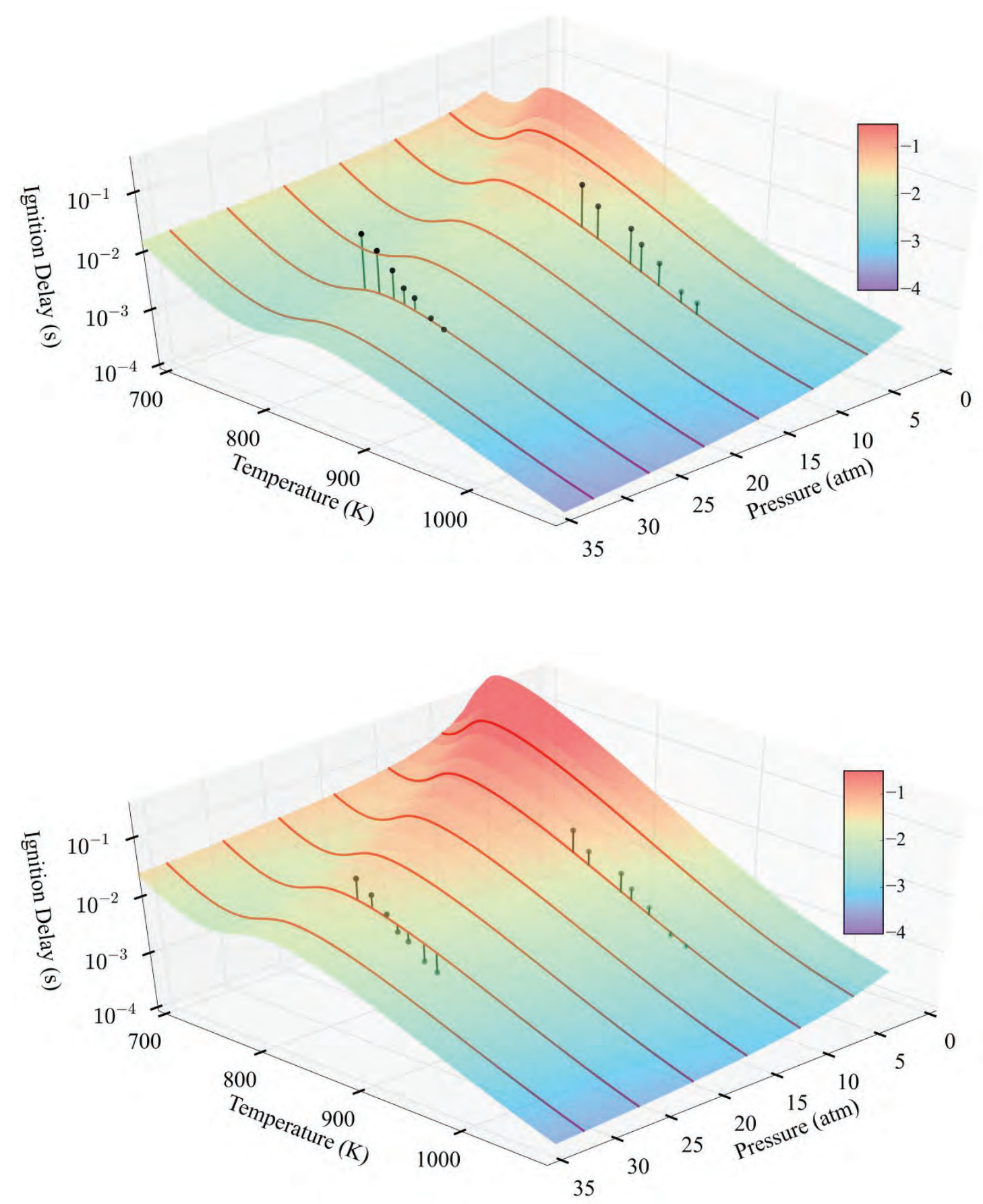
Figure 18

(a) Comparison of Experimental and Simulated Ignition Delays

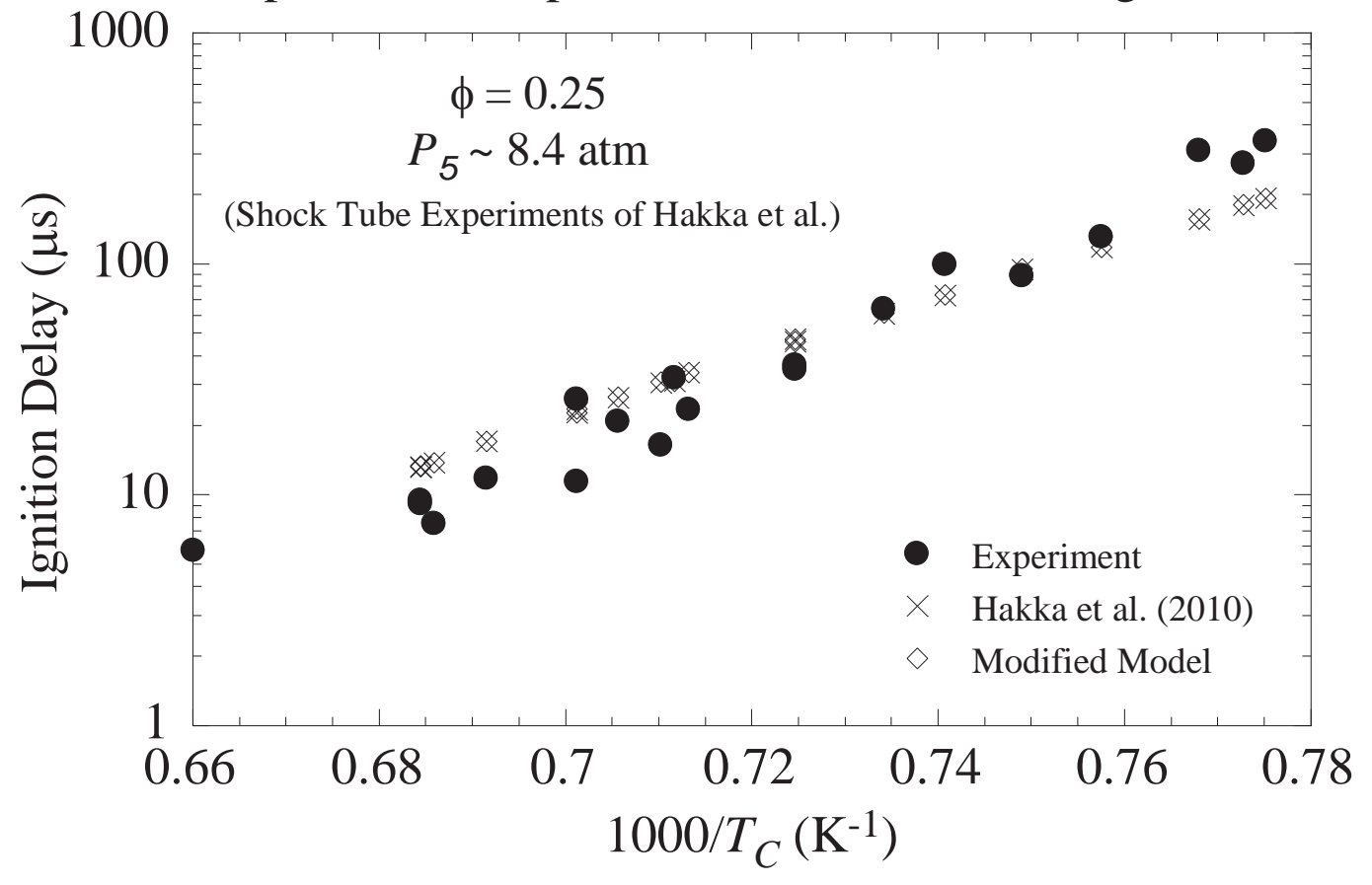

(b) Comparison of Experimental and Simulated Ignition Delays

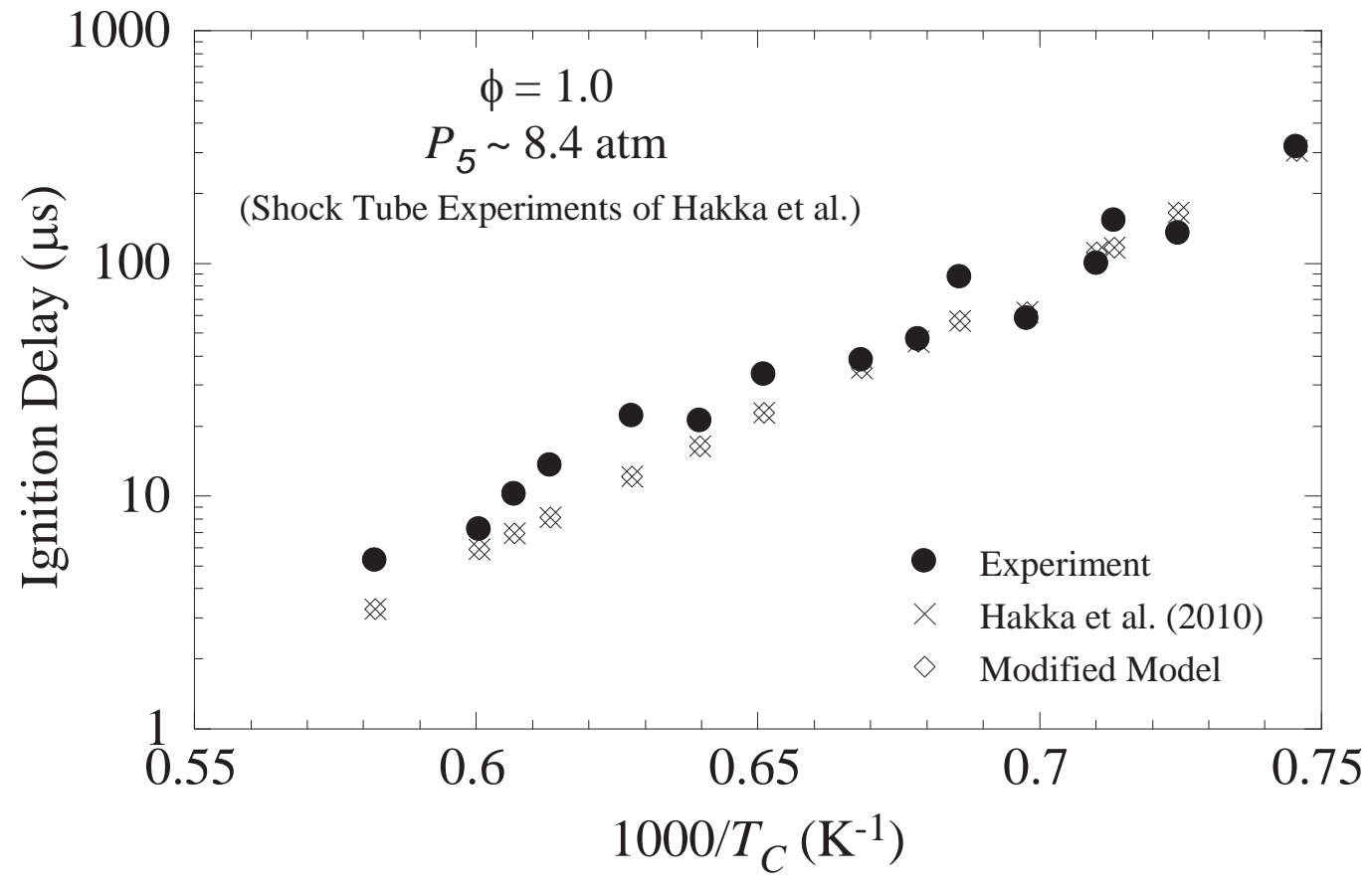


Figure 19

Rate Constants for $\mathrm{H}$ atom abstraction by $\mathrm{HO}_{2}$ on the $\alpha$ site of Methyl Butanoate

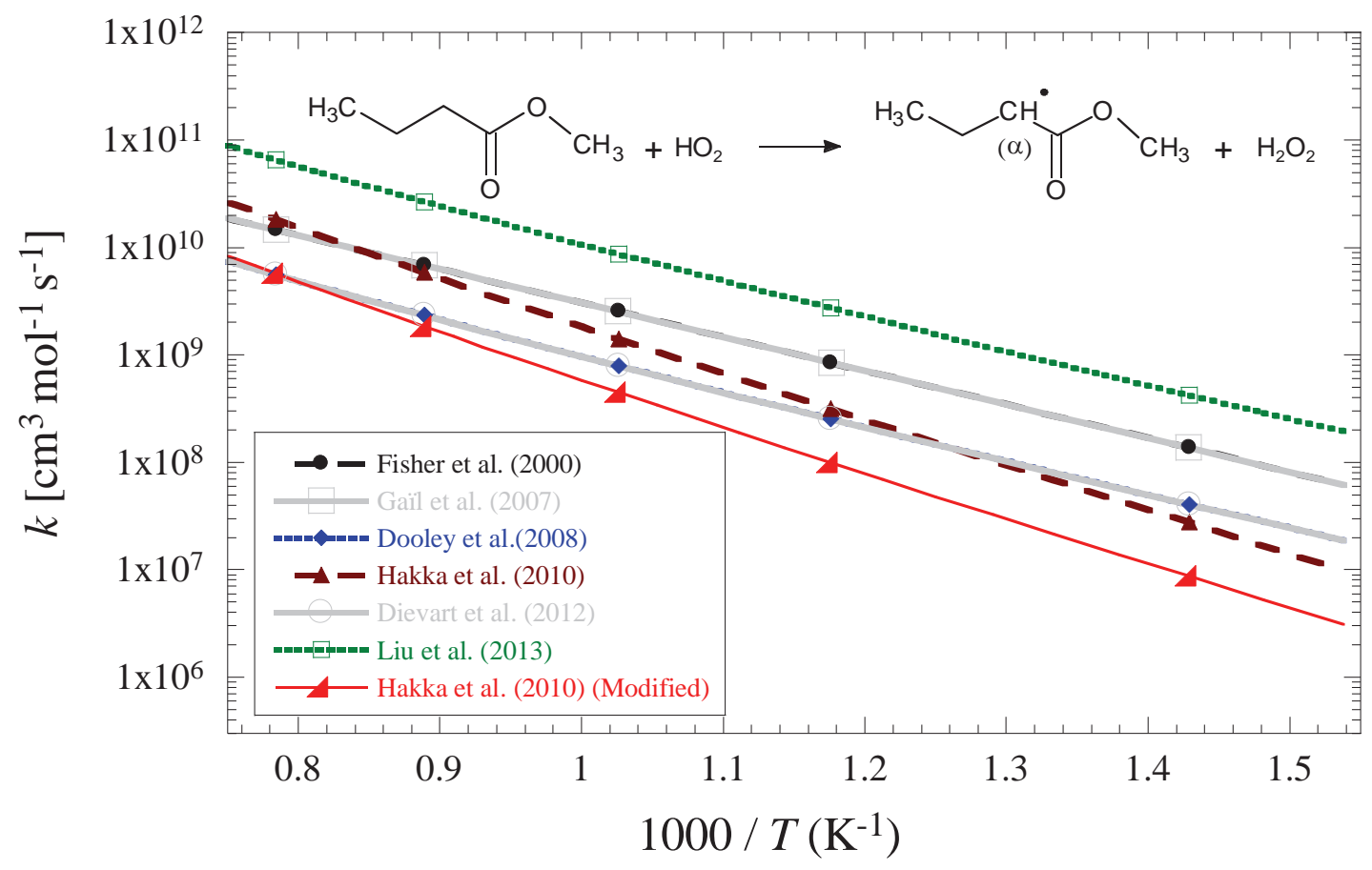


Table 1

\begin{tabular}{|c|c|c|c|c|c|c|c|}
\hline \multicolumn{8}{|c|}{ Ignition Delays for Methyl Butanoate in Argon-Oxygen Mixtures } \\
\hline Fuel & $\mathrm{O}_{2}$ & $\mathrm{Ar}$ & $\phi$ & $T_{C}$ & $P_{C}$ & $\tau$ & $\pm \sigma_{\tau}$ \\
\hline \multicolumn{3}{|c|}{ Mole Percentage (\%) } & & $(\mathrm{K})$ & (bar) & (ms) & (ms) \\
\hline 0.80 & 20.84 & 78.36 & 0.25 & 966 & 15 & 117.4 & 3.6 \\
\hline 0.80 & 20.84 & 78.36 & 0.25 & 974 & 15 & 53.0 & 1.35 \\
\hline 0.80 & 20.84 & 78.36 & 0.25 & 1007 & 15 & 22.2 & 1.51 \\
\hline 0.80 & 20.84 & 78.36 & 0.25 & 1031 & 15 & 11.2 & 0.47 \\
\hline 0.80 & 20.84 & 78.36 & 0.25 & 1093 & 15 & 3.2 & 0.07 \\
\hline 0.80 & 20.84 & 78.36 & 0.25 & 1112 & 15 & 1.8 & 0.13 \\
\hline 0.80 & 20.84 & 78.36 & 0.25 & 900 & 30 & 83.2 & 3.97 \\
\hline 0.80 & 20.84 & 78.36 & 0.25 & 909 & 30 & 48.8 & 1.46 \\
\hline 0.80 & 20.84 & 78.36 & 0.25 & 926 & 30 & 38.9 & 0.50 \\
\hline 0.80 & 20.84 & 78.36 & 0.25 & 938 & 30 & 27.2 & 1.04 \\
\hline 0.80 & 20.84 & 78.36 & 0.25 & 959 & 30 & 14.5 & 0.82 \\
\hline 0.80 & 20.84 & 78.36 & 0.25 & 986 & 30 & 7.5 & 0.23 \\
\hline 0.80 & 20.84 & 78.36 & 0.25 & 1016 & 30 & 4.0 & 0.14 \\
\hline 0.80 & 20.84 & 78.36 & 0.25 & 1053 & 30 & 1.5 & 0.13 \\
\hline 0.80 & 20.84 & 78.36 & 0.25 & 917 & 45 & 27.3 & 0.55 \\
\hline 0.80 & 20.84 & 78.36 & 0.25 & 932 & 45 & 17.8 & 0.60 \\
\hline 0.80 & 20.84 & 78.36 & 0.25 & 947 & 45 & 12.5 & 0.63 \\
\hline 0.80 & 20.84 & 78.36 & 0.25 & 956 & 45 & 7.5 & 0.49 \\
\hline 0.80 & 20.84 & 78.36 & 0.25 & 983 & 45 & 4.1 & 0.33 \\
\hline 0.80 & 20.84 & 78.36 & 0.25 & 1008 & 45 & 2.1 & 0.99 \\
\hline 0.80 & 20.84 & 78.36 & 0.25 & 883 & 75 & 34.5 & 1.71 \\
\hline 0.80 & 20.84 & 78.36 & 0.25 & 912 & 75 & 15.8 & 0.47 \\
\hline 0.80 & 20.84 & 78.36 & 0.25 & 923 & 75 & 12.1 & 0.95 \\
\hline 0.80 & 20.84 & 78.36 & 0.25 & 936 & 75 & 6.8 & 0.30 \\
\hline 0.80 & 20.84 & 78.36 & 0.25 & 950 & 75 & 5.3 & 0.76 \\
\hline 0.80 & 20.84 & 78.36 & 0.25 & 969 & 75 & 4.0 & 0.35 \\
\hline 1.59 & 20.67 & 77.74 & 0.50 & 938 & 15 & 63.5 & 2.25 \\
\hline 1.59 & 20.67 & 77.74 & 0.50 & 958 & 15 & 28.1 & 1.47 \\
\hline 1.59 & 20.67 & 77.74 & 0.50 & 972 & 15 & 16.2 & 0.59 \\
\hline 1.59 & 20.67 & 77.74 & 0.50 & 995 & 15 & 10.4 & 0.84 \\
\hline 1.59 & 20.67 & 77.74 & 0.50 & 1019 & 15 & 7.2 & 0.52 \\
\hline 1.59 & 20.67 & 77.74 & 0.50 & 872 & 30 & 64.3 & 1.76 \\
\hline 1.59 & 20.67 & 77.74 & 0.50 & 883 & 30 & 46.6 & 1.76 \\
\hline 1.59 & 20.67 & 77.74 & 0.50 & 891 & 30 & 34.8 & 1.16 \\
\hline 1.59 & 20.67 & 77.74 & 0.50 & 904 & 30 & 23.4 & 0.85 \\
\hline
\end{tabular}




\begin{tabular}{|l|l|l|l|l|l|l|l|}
\hline 1.59 & 20.67 & 77.74 & 0.50 & 915 & 30 & 15.2 & 0.68 \\
\hline 1.59 & 20.67 & 77.74 & 0.50 & 928 & 30 & 12.2 & 0.83 \\
\hline 1.59 & 20.67 & 77.74 & 0.50 & 940 & 30 & 9.8 & 0.61 \\
\hline 1.59 & 20.67 & 77.74 & 0.50 & 950 & 30 & 7.4 & 0.32 \\
\hline 1.59 & 20.67 & 77.74 & 0.50 & 965 & 30 & 5.5 & 0.37 \\
\hline 1.59 & 20.67 & 77.74 & 0.50 & 1001 & 30 & 2.4 & 0.28 \\
\hline 3.13 & 20.35 & 76.52 & 1.00 & 881 & 15 & 76.4 & 1.20 \\
\hline 3.13 & 20.35 & 76.52 & 1.00 & 896 & 15 & 41.8 & 0.88 \\
\hline 3.13 & 20.35 & 76.52 & 1.00 & 927 & 15 & 27.9 & 2.07 \\
\hline 3.13 & 20.35 & 76.52 & 1.00 & 937 & 15 & 17.5 & 0.85 \\
\hline 3.13 & 20.35 & 76.52 & 1.00 & 954 & 15 & 10.8 & 0.75 \\
\hline 3.13 & 20.35 & 76.52 & 1.00 & 975 & 15 & 4.9 & 0.43 \\
\hline 3.13 & 20.35 & 76.52 & 1.00 & 990 & 15 & 3.9 & 0.62 \\
\hline 3.13 & 20.35 & 76.52 & 1.00 & 833 & 30 & 57.7 & 2.32 \\
\hline 3.13 & 20.35 & 76.52 & 1.00 & 847 & 30 & 37.4 & 1.13 \\
\hline 3.13 & 20.35 & 76.52 & 1.00 & 861 & 30 & 21.6 & 0.61 \\
\hline 3.13 & 20.35 & 76.52 & 1.00 & 871 & 30 & 12.6 & 1.06 \\
\hline 3.13 & 20.35 & 76.52 & 1.00 & 881 & 30 & 10.0 & 0.66 \\
\hline 3.13 & 20.35 & 76.52 & 1.00 & 896 & 30 & 5.7 & 0.47 \\
\hline 3.13 & 20.35 & 76.52 & 1.00 & 908 & 30 & 4.4 & 0.46 \\
\hline
\end{tabular}




\section{References}

[1] U. S. E. I. Administration, Annual Energy Outlook 2014 with Projections to 2040, DOE/EIA0383(2014),U.S. Energy Information Administration, U. S. E. I. Administration, 2014.

[2] K. Kohse-Hoinghaus, P. Osswald, T. A. Cool, T. Kasper, N. Hansen, F. Qi, C. K. Westbrook, P. R. Westmoreland, Angew Chem Int Edit 49 (21) (2010) 3572-3597.

[3] L. Coniglio, H. Bennadji, P. A. Glaude, O. Herbinet, F. Billaud, Prog Energ Combust 39 (4) (2013) 340-382.

[4] H. Tao, K. C. Lin, Combust Flame 161 (9) (2014) 2270-2287.

[5] W. Liu, R. Sivaramakrishnan, M. J. Davis, S. Som, D. E. Longman, T. F. Lu, P Combust Inst 34 (1) (2013) 401-409.

[6] Y. Lee, K. Y. Huh, Fuel 113 (0) (2013) 537-545.

[7] P. Dievart, S. H. Won, J. Gong, S. Dooley, Y. G. Ju, P Combust Inst 34 (2013) 821-829.

[8] M. A. Ali, A. Violi, J Org Chem 78 (12) (2013) 5898-5908.

[9] W. Yu, G. Chen, Z. H. Huang, Z. Y. Chen, J. Gong, J. Z. Yang, Z. D. Wang, F. Qi, Combust Flame 159 (1) (2012) 44-54.

[10] R. Grana, A. Frassoldati, C. Saggese, T. Faravelli, E. Ranzi, Combust Flame 159 (7) (2012) 2280-2294.

[11] C. K. Westbrook, F. L. Dryer, Prog Energ Combust 10 (1) (1984) 1-57.

[12] S. Dooley, H. J. Curran, J. M. Simmie, Combust Flame 153 (1-2) (2008) 2-32.

[13] K. HadjAli, M. Crochet, G. Vanhove, M. Ribaucour, R. Minetti, P Combust Inst 32 (1) (2009) 239-246.

[14] S. M. Walton, M. S. Wooldridge, C. K. Westbrook, P Combust Inst 32 (2009) 255-262.

[15] B. Akih-Kumgeh, J. M. Bergthorson, Energ Fuel 24 (4) (2010) 2439-2448.

[16] D. F. Davidson, S. C. Ranganath, K. Y. Lam, M. Liaw, Z. Hong, R. K. Hanson, J Propul Power 26 (2) (2010) 280-287.

[17] M. H. Hakka, H. Bennadji, J. Biet, M. Yahyaoui, B. Sirjean, V. Warth, L. Coniglio, O. Herbinet, P. A. Glaude, F. Billaud, F. Battin-Leclerc, Int J Chem Kinet 42 (4) (2010) 226-252.

[18] B. Akih-Kumgeh, J. M. Bergthorson, Combust Flame 158 (6) (2011) 1037-1048.

[19] A. Farooq, D. F. Davidson, R. K. Hanson, L. K. Huynh, A. Violi, P Combust Inst 32 (1) (2009) 247-253.

[20] A. Farooq, W. Ren, K. Y. Lam, D. F. Davidson, R. K. Hanson, C. K. Westbrook, Combust Flame 159 (11) (2012) 3235-3241. 
[21] K. Y. Lam, D. F. Davidson, R. K. Hanson, J Phys Chem A 116 (50) (2012) 12229-12241.

[22] S. M. Sarathy, S. Gaïl, S. A. Syed, M. J. Thomson, P. Dagaut, P Combust Inst 31 (1) (2007) 1015-1022.

[23] S. Gaïl, S. M. Sarathy, M. J. Thomson, P. Dievart, P. Dagaut, Combust Flame 155 (4) (2008) 635-650.

[24] V. I. Golovitchev, J. F. Yang, Biotechnol Adv 27 (5) (2009) 641-655.

[25] S. Um, S. W. Park, Energ Fuel 24 (2) (2009) 916-927.

[26] S. Som, D. E. Longman, A. I. Ramírez, S. K. Aggarwal, Fuel 89 (12) (2010) 4014-4024.

[27] Y. Ra, R. D. Reitz, Combust Flame 158 (1) (2011) 69-90.

[28] Y. Ren, X. G. Li, P I Mech Eng D-J Aut 225 (D4) (2011) 531-543.

[29] S. Som, D. E. Longman, Energ Fuel 25 (4) (2011) 1373-1386.

[30] S. Zhang, L. J. Broadbelt, I. P. Androulakis, M. G. Ierapetritou, Energ Fuel 26 (2) (2012) 976983.

[31] M. Johansson, J. Yang, R. Ochoterena, S. Gjirja, I. Denbratt, Fuel 106 (0) (2013) 293-302.

[32] Y. Zhang, A. L. Boehman, Combust Flame 159 (4) (2012) 1619-1630.

[33] Y. Zhang, A. L. Boehman, Combust Flame 157 (3) (2010) 546-555.

[34] Y. Zhang, Y. Yang, A. L. Boehman, Combust Flame 156 (6) (2009) 1202-1213. 128.

[35] J. P. Szybist, A. L. Boehman, D. C. Haworth, H. Koga, Combust Flame 149 (1-2) (2007) 112-

[36] Y. L. Wang, D. J. Lee, C. K. Westbrook, F. N. Egolfopoulos, T. T. Tsotsis, Combust Flame 161 (3) (2014) 810-817.

[37] W. Yu, G. Chen, Z. Huang, Z. Chen, J. Gong, J. Yang, Z. Wang, F. Qi, Combust Flame 159 (1) (2012) 44-54.

[38] B. Yang, C. K. Westbrook, T. A. Cool, N. Hansen, K. Kohse-Hoinghaus, Phys Chem Chem Phys 13 (15) (2011) 6901-6913.

[39] Y. L. Wang, Q. Feng, F. N. Egolfopoulos, T. T. Tsotsis, Combust Flame 158 (8) (2011) $1507-$ 1519.

[40] W. Liu, A. P. Kelley, C. K. Law, P Combust Inst 33 (1) (2011) 995-1002.

[41] J. Wang, B. Yang, T. A. Cool, N. Hansen, Int J Mass Spectrom 292 (1-3) (2010) 14-22.

[42] C. K. Westbrook, W. J. Pitz, P. R. Westmoreland, F. L. Dryer, M. Chaos, P. Osswald, K. KohseHoinghaus, T. A. Cool, J. Wang, B. Yang, N. Hansen, T. Kasper, P Combust Inst 32 (2009) 221-228. 
[43] S. Dooley, M. Uddi, S. H. Won, F. L. Dryer, Y. G. Ju, Combust Flame 159 (4) (2012) 13711384.

[44] T. I. Farouk, Y. C. Liu, A. J. Savas, C. T. Avedisian, F. L. Dryer, P Combust Inst 34 (1) (2013) 1609-1616.

[45] Q. Feng, A. Jalali, A. M. Fincham, Y. L. Wang, T. T. Tsotsis, F. N. Egolfopoulos, Combust Flame 159 (5) (2012) 1876-1893.

[46] M. M. Maricq, Combust Flame 158 (1) (2011) 105-116.

[47] A. M. El-Nahas, M. V. Navarro, J. M. Simmie, J. W. Bozzelli, H. J. Curran, S. Dooley, W. Metcalfe, J Phys Chem A 111 (19) (2007) 3727-3739.

[48] L. K. Huynh, A. Violi, J Org Chem 73 (1) (2008) 94-101.

[49] A. Osmont, M. Yahyaoui, L. Catoire, I. Gokalp, M. T. Swihart, Combust Flame 155 (1-2) (2008) 334-342.

[50] C. J. Hayes, D. R. Burgess, P Combust Inst 32 (2009) 263-270.

[51] J. Mendes, C. W. Zhou, H. J. Curran, J Phys Chem A 117 (51) (2013) 14006-14018.

[52] A. K. Das, M. Uddi, C.-J. Sung, Combust Flame 159 (12) (2012) 3493-3501.

[53] G. Mittal, C. J. Sung, Combust Sci Technol 179 (3) (2007) 497-530.

[54] K. Kumar, G. Mittal, C. J. Sung, Combust Flame 156 (6) (2009) 1278-1288.

[55] CHEMKIN-III

[56] SENKIN

[57] E. M. Fisher, W. J. Pitz, H. J. Curran, C. K. Westbrook, P Combust Inst 28 (2) (2000) 15791586.

[58] S. Gaïl, M. J. Thomson, S. M. Sarathy, S. A. Syed, P. Dagaut, P. Dievart, A. J. Marchese, F. L. Dryer, P Combust Inst 31 (2007) 305-311.

[59] P. Dievart, S. H. Won, S. Dooley, F. L. Dryer, Y. G. Ju, Combust Flame 159 (5) (2012) 17931805.

[60] S. M. Walton, D. M. Karwat, P. D. Teini, A. M. Gorny, M. S. Wooldridge, Fuel 90 (5) (2011) 1796-1804.

[61] R. I. Cukier, C. M. Fortuin, K. E. Shuler, A. G. Petschek, J. H. Schaibly, The Journal of Chemical Physics 59 (8) (1973) 3873-3878.

[62] J. H. Schaibly, K. E. Shuler, The Journal of Chemical Physics 59 (8) (1973) 3879-3888.

[63] G. J. McRae, J. W. Tilden, J. H. Seinfeld, Comput Chem Eng 6 (1) (1982) 15-25. 
[64] A. Saltelli, S. Tarantola, K. P. S. Chan, Technometrics 41 (1) (1999) 39-56.

[65] Joint Research Centre (JRC), Institute for the Protection and Security of the Citizen (IPSC); Other Routines For Sensitivity Analysis : Classic FAST (first order effects) in F77. http://ipsc.jrc.ec.europa.eu/?id=756 (10-August, 2014)

[66] D. L. Baulch, C. T. Bowman, C. J. Cobos, R. A. Cox, T. Just, J. A. Kerr, M. J. Pilling, D. Stocker, J. Troe, W. Tsang, R. W. Walker, J. Warnatz, J Phys Chem Ref Data 34 (3) (2005) 757-1397.

[67] R. Sivaramakrishnan, J. V. Michael, The Journal of Physical Chemistry A 113 (17) (2009) 50475060.

[68] H.-H. Carstensen, A. M. Dean, O. Deutschmann, P Combust Inst 31 (1) (2007) 149-157.

[69] J. P. Orme, H. J. Curran, J. M. Simmie, The Journal of Physical Chemistry A 110 (1) (2006) 114-131.

[70] A. M. Dean, J. W. Bozzelli, in: Gas-Phase Combustion Chemistry, W. C. Gardiner, (Ed.) Springer: 1999.

[71] O. Herbinet, W. J. Pitz, C. K. Westbrook, Combust Flame 154 (3) (2008) 507-528. 